\title{
EL INTERÉS SUPERIOR DEL NIÑO EN EL MARCO DE LA CONVENCIÓN INTERNACIONAL SOBRE LOS DERECHOS DEL NIÑO Y SU CONFIGURACIÓN EN EL DERECHO CIVIL CHILENO
}

\author{
THE BEST INTEREST OF THE CHILD IN THE FRAMEWORK OF THE \\ INTERNATIONAL CONVENTION ON THE RIGHTS OF THE CHILD \\ AND ITS CONFIGURATION IN THE CHILEAN CIVIL LAW
}

\author{
IsAaC RaVETLlat Ballesté* \\ Ruperto Pinochet Olave ${ }^{* *}$
}

\begin{abstract}
RESUMEN: El objetivo fundamental de este estudio se centra en relatar la forma en cómo ha operado la recepción del principio del interés superior del niño en el ordenamiento jurídico civil chileno. Inicialmente, esta cláusula abstracta se ha configurado en Chile (tal y como ha acaecido mayoritariamente en los sistemas normativos europeos continentales) como una cláusula general o como un concepto jurídico indeterminado, difícil de definir y en mayor medida de aplicar. Posteriormente, y como respuesta a la inseguridad jurídica provocada por la necesidad de proceder a esa concreción de carácter casuístico, el legislador parece haberse decantado, en particular tras la reforma introducida en el Código Civil por la Ley 20.680, de 21 de junio de 2013, hacia un mayor nivel de concreción positiva del término, tendiendo con ello a aproximarse a modelos más propios del derecho anglosajón. La forma en como este principio irrumpe, evoluciona y se consolida en el marco internacional de referencia, en particular en el texto de la Convención sobre los Derechos del Niño y su ulterior desarrollo en la Observación General No 14 del Comité de los Derechos del Niño, marcan un claro precedente que debe ser tomado en consideración por parte del intérprete chileno a la hora de configurar y dotar de significación a este verdadero principio rector del Derecho.
\end{abstract}

Palabras clave: Interés superior del niño, concepto jurídico indeterminado, Convención sobre los Derechos del Niño, Comité de los Derechos del Niño.

ABSTRACT: The main objective of this study focuses on telling how the reception of the best interests of the child has operated in the Chilean civil law. Initially, this abstract clause is set in Chile (as has occurred mainly in continental European legal systems) as a general term or an indeterminate legal concept, difficult to define and implement. Subsequently, and in response to the legal uncertainty caused by the need to proceed to the realization of a casuistic character, the legislator seems to have opted, in particular following the reform introduced in the Civil Code by Law 20.680, of June 21, 2013, towards a higher level of positive realization of the term, thereby tending to approach more typical models of common law. The way, in which this

\footnotetext{
* Licenciado en Derecho, Universidad de Barcelona; Doctor en Derecho, Universidad de Barcelona; Profesor de Derecho Civil de la Facultad de Ciencias Jurídicas y Sociales de la Universidad de Talca. Dirección postal: 2 Norte 685, Talca. Correo electrónico: iravetllat@utalca.cl.

** Licenciado en Ciencias Jurídicas y Sociales, Universidad de Chile; Doctor en Derecho, Universidad de Barcelona; Profesor de Derecho Civil de la Facultad de Ciencias Jurídicas y Sociales de la Universidad de Talca. Dirección postal: 2 Norte 685, Talca. Correo electrónico: rpinoche@utalca.cl.
} 
principle breaks, evolves and consolidates in the international framework, to be more concrete, in the text of the Convention on the Right of the Child and its further development in the General Comment $\mathrm{n}^{\mathrm{o}} .14$ of the Committee on the Rights of the Child, stands a clear precedent that must be taken into consideration by the Chilean interpreter when configuring and providing real significance to this general principle.

Key words: Interest of the child, indeterminate legal concept, Convention on the Rights of the Child, Committee on the Rights of the Child.

\section{INTRODUCCIÓN}

Es bien sabido que buena parte de la doctrina ha puesto en tela de juicio la efectiva utilidad del concepto jurídico indeterminado del interés superior del niño ${ }^{1}$. Cierto es que la verdadera fuerza atribuida a este principio reside en su carácter eminentemente abstracto, aspecto este que facilita su adaptación a los diferentes supuestos de hecho que puedan ir suscitándose; no obstante, esa misma circunstancia le ha valido un gran número de críticas fundamentadas, esencialmente, en su alto grado de indeterminación ${ }^{2}$.

Estamos, pues, ante un concepto no pacífico, de difícil concreción, que ha atraído la atención de no pocos autores, deseosos de analizar pormenorizadamente si el mentado principio rector -siguiendo la caracterización que le ha atribuido el propio Comité de los Derechos del $\mathrm{Niño}^{3}$ - es realmente de aplicación efectiva en nuestra práctica cotidiana y en caso de ser así, cuál es el modelo de implementación en que ello se viene operando por parte de los diferentes actores sociales que inciden en la vida del niño, niña o adolescente, para, de este modo, evitar que este concepto se convierta en lo que Carbonnier definió

1 En tal sentido: Cillero (1999) p. 46; Díaz de Valdés (2010) pp. 294-295; Fortin (2009) pp. 292-293; Pettigiani (1998) p. 16; Van Bueren (1995) pp. 48-49; y, Mnookin (1985) pp. 17-18.

2 En palabras de Eekelaar, la naturaleza subjetiva de las facultades atribuidas a los jueces les permiten valorar y sopesar libremente los diferentes elementos tomados en consideración para concretar, caso por caso, la cláusula abstracta del interés superior del menor. Eekelaar (1992) p. 125. Por su parte, Pérez nos recuerda que el recurso, por parte de las autoridades internas de cada Estado, a la noción del interés superior del menor implica el riesgo de traducir manifestaciones de la particularidad cultural y social de una comunidad nacional dada y por ende, en el fondo, de formular juicios de valor subjetivos sobre otra comunidad nacional. PérEz (2000) p. 1140. Por último, Del Picó sostiene que hay que resaltar el carácter extremadamente abierto y carente de determinación legal que presenta el principio del interés superior del niño. La explicación de esta aparente falencia normativa es preciso buscarla, en palabras del mismo autor, en la ausencia de uniformidad tanto de los sujetos a los cuales debe aplicarse, como de las circunstancias sociales que les condicionan o determinan. Del Picó (2010) p. 134. Por su parte, la jurisprudencia chilena viene identificando este principio como un concepto jurídico indeterminado y de contornos imprecisos que se delimita por las circunstancias de cada caso en particular y, en la especie, por aquello que resulte más aconsejable para asegurar la protección de lo derechos fundamentales del niño y posibilitar la satisfacción de todos los requerimientos de una vida normal orientada al equilibrado desarrollo de su personalidad en un ambiente de afecto, contención y formación integral. En este sentido vid. por todas la Sentencia de la Corte Suprema de 10 de septiembre de 2014.

3 Cfr. Villagrasa (2012) pp. 18-19. En este mismo sentido se manifiesta el propio Comité de los Derechos del Niño tanto en su Observación General no. 5 (2003), sobre medidas generales de aplicación de la Convención sobre los Derechos del Niño, párr. 12; como en su Observación General no 12 (2009), sobre el derecho del niño a ser escuchado, párr. 2. 
como una noción mágica, evanescente, que puede dar lugar a la arbitrariedad jurídica y al abuso de derecho ${ }^{4}$.

Para dar respuesta a todos estos interrogantes, el Comité de los Derechos del Niño adoptó, el 29 de mayo de 2013, la Observación General nº. 14, sobre el derecho del niño a que su interés superior sea una consideración primordial, en la que se efectúa un comentario exhaustivo del citado principio general contenido en el párrafo primero del artículo 3 de la Convención sobre los Derechos del Niño5.

Efectivamente, la esperada Observación General no 14 gira en torno al concepto dinámico ${ }^{6}$ del interés superior del niño, con la finalidad última de facilitar a todos los agentes sociales su adecuada interpretación y puesta en escena; garantizando, así, el disfrute pleno y efectivo de todos los derechos de los que niños, niñas y adolescentes son titulares.

No obstante, y sin desmerecer en absoluto el papel crucial que está llamado a desempeñar el mentado documento emanado del Comité ginebrino durante los próximos años, consideramos indispensable, para poder con ello llegar a comprender su verdadero alcance y significación, el proceder al estudio minucioso de cuál ha sido la evolución seguida por este concepto jurídico indeterminado en el contexto internacional durante el devenir de los últimos decenios.

Del análisis de la normativa internacional se deduce que el interés del menor ha experimentado un proceso de transformación profunda, pasando de ser un principio inexistente e inimaginable, a convertirse, posteriormente, en un principio implícito en buen número de normas y resoluciones judiciales, para, finalmente, en el estadio actual, convertirse en una realidad contemplada expresamente en nuestro sistema normativo, basada en una concepción teleológica del Derecho.

En suma, la formulación jurídica del principio del interés superior del niño supone la constatación de un principio general del Derecho, y de ahí que pueda ser considerado como un medio de información, de integración y de interpretación, tanto de las normas e instituciones en que esta cláusula general aparece incorporada, como de las instituciones y relaciones cotidianas que se ven afectadas, ya sea para detectar conflictos (antes desapercibidos o infravalorados), ya sea para solventar problemas en los que resulte afectado ${ }^{7}$.

\footnotetext{
4 Cfr. Carbonnier (1960) p. 673.

5 CRC/C/GC/14, de 29 de mayo de 2013.

6 La Observación General no. 14, en su párrafo 1º, utiliza la locución “concepto dinámico” para referirse al interés superior del menor. En realidad esta expresión es utilizada con idéntica significación que la contenida en la más conocida noción de "concepto jurídico indeterminado". El empleo de la voz "concepto dinámico" procede, casi con toda seguridad, de la traducción literal de la versión inglesa "dynamic concept", puesto que en el lenguaje jurídico anglosajón no existe figura alguna conocida bajo la idea de concepto jurídico indeterminado.

7 En opinión de Gómez de la Torre, puede otorgarse una triple función al principio del interés superior del niño: es una garantía para el menor, debido a que toda decisión que le concierna debe considerar, fundamentalmente, sus derechos; asimismo, es una norma orientadora que no solo obliga a los legisladores y jueces sino a todas las instituciones públicas y privadas; y, por último, también debe ser vista como una norma de interpretación y de resolución de conflictos. GÓMEZ DE LA TORRE (2000) p. 23. Por su parte, Gatica y Chaimovic afirman que el llamado interés superior del niño debe ser entendido como un término relacional o comunicacional, y significa que en casos de conflicto de derechos de igual rango, el derecho de prioridad del interés superior del niño prima sobre cualquier otro que pueda afectar derechos fundamentales del niño/a.
} 
Una vez efectuada esa introspección a los antecedentes normativos internacionales que dieron como resultado la redacción del hoy vigente artículo 3 de la Convención sobre los Derechos del Niño, así como de su posterior desarrollo en la Observación General no 14 (2013) del Comité sobre los Derechos del Niño, nos parece oportuno, para completar con ello el presente estudio, adentrarnos en las diferentes técnicas legislativas existentes para determinar en qué consiste el interés superior del niño. Así, el propio Comité de los Derechos del Niño reconoce en sus resoluciones dos medios o sistemas claramente diferenciados entre sí: por un lado, su identificación mediante una serie de indicadores legales, representativos de lo que la sociedad considera como los factores más importantes y significativos del mismo, que vienen a proporcionar unas pautas a seguir en la toma de todas aquellas decisiones donde este principio deba entrar en juego; y por otro, a través de una cláusula general, en la que solo se impone la necesidad de actuar en interés del menor, pero sin reconocérsele un contenido específico.

Este último es, precisamente, el criterio utilizado por el ordenamiento jurídico civil chileno en el que el legislador incide escasamente en el contenido particular del principio y se configura como un concepto jurídico indeterminado, con remisión, para su precisión efectiva, al momento y a la persona que deba aplicar la norma y por ende el concepto, con la correspondiente adecuación del mandato legal a cada supuesto determinado, a la amplia variedad de personas implicadas y a la pluralidad de situaciones que pudieran suscitarse ${ }^{8}$.

\section{IRRUPCIÓN DE LA CLÁUSULA ABSTRACTA DEL INTERÉS SUPERIOR DEL NIÑO EN EL CONTEXTO JURÍDICO INTERNACIONAL}

A diferencia de lo acaecido con otros principios y reglas jurídicas aplicables en materia de atención y protección a la infancia y la adolescencia cuya aparición y consolidación pueden constatarse, sin ningún género de dudas, en el contexto internacional, operándose a posteriori su recepción por parte de los diferentes ordenamientos jurídicos domésticos; al referirnos al interés superior del niño, por el contrario, debemos subrayar que el itinerario recorrido por este principio ordenador del sistema es precisamente el inverso9 . Así, tradicionalmente, este concepto jurídico indeterminado se ha caracterizado por ser un elemento

\footnotetext{
Así, concluyen estas autoras, ni el interés de los progenitores, ni el de la sociedad, ni el del Estado pueden ser considerados prioritarios en relación a los derechos del niño/a. Gatıca y Chaimovic (2002) pp. 14-16. Por último, Rodríguez, refiriéndose de forma específica al ámbito del cuidado personal de los hijos y al derecho de los progenitores a mantener con ellos una relación directa y regular, apunta que el interés superior del niño en este contexto se convierte también en un criterio, baremo o standard de adjudicación de litigios (artículo 242 inciso 2o del Código civil y artículo 16 de la Ley creadora de los Tribunales de Familia). Rodríguez (2009) p. 566.

${ }^{8}$ Desde una perspectiva nacional, Baeza, en un intento de definición señala que el interés superior del niño es el conjunto de bienes necesarios para el desarrollo integral y la protección de la persona del menor de edad y, en general, de sus derechos, que buscan su mayor bienestar. BAEZA (2001) p. 356.

9 No obstante, algunos autores afirman que se trataría de una norma de derecho internacional consuetudinario que solo habría sido positivizada por la Declaración Universal de los Derechos del Niño y la Convención sobre los Derechos del Niño. Aguilar (2008) p. 231.
} 
esencial en el Derecho de familia del calificado como mundo jurídico occidental, muy especialmente del eurocontinental ${ }^{10}$.

En Francia, sin ir más lejos, la evolución de su normativa civil desde mediados del siglo XIX revela la clara voluntad del legislador galo de hacer del interés de la persona menor de edad un concepto abstracto elevado al rango de principio general del derecho. Y es precisamente en el Derecho civil francés donde aparece por vez primera y de forma más evidente esta cláusula jurídica, concretamente en las leyes que vinieron a limitar la figura de la patria potestad (Ley de 24 de julio de 1889). En consecuencia, un siglo antes de la aprobación de la Convención sobre los Derechos del Niño por parte de la Asamblea General de las Naciones Unidas, en el ordenamiento jurídico francés ya era posible encontrar numerosas referencias al principio del interés superior del niño en la regulación de materias tales como el derecho a la identidad (nombre y apellidos), la filiación biológica y adoptiva $y$, naturalmente, todo lo referente a la autoridad parental ${ }^{11}$.

En Italia, por su parte, la noción del interés superior del niño empezó a ser empleada a partir de la Ley de adopción de 1967, en la que la alusión a este principio sirvió para contrastar y poner fin a caducos y denostados prejuicios e incrustaciones culturales todavía presentes en el derecho transalpino de la época ${ }^{12}$.

Finalmente, en el Reino Unido el welfare principle (principio del bienestar) fue incorporado en la Common Law a principios del siglo XX como una consideración primordial (paramount consideration) a tener presente en los supuestos de custodia. La legislación inmediatamente subsiguiente no pudo sino reflejar esa misma visión. Así se puso de manifiesto en la Guardianship of Infants Act de 1925 en la que expresamente se estatuye que "in making decisions relating to the custody and upbrining of children, the courts should make the child's welfare the first and paramount (la primera y primordial) consideration"13.

10 Cfr. Ravetllat (2012) pp. 89-108. En igual medida, Alston nos recuerda el peligro de usar las previsiones incluidas en los derechos domésticos para interpretar el artículo 3 de la Convención sobre los Derechos del Niño, precepto en el que se regula el principio del interés superior del menor. Una de las razones, prosigue este autor, que aconsejarían la limitación del valor de la jurisprudencia nacional como elemento aclarativo del texto de la Convención, es que la cláusula abstracta del interés superior del menor se ha aplicado en los derechos internos a un número reducido de supuestos (en particular a los casos de custodia) mientras que el Tratado Internacional pretende su toma en consideración de manera mucho más amplia y generalizada. AlsTON (1994) pp. 2-3. Por último, Díaz de Valdés asevera que expresiones tales como welfare of the child, l'intérêt supérieur de l'enfant, entre otras, demostrarían la extendida influencia del principio del interés superior del niño en los sistemas jurídicos de diversos países. Díaz de VALDÉs (2010) p. 291.

11 Cfr. Rubellin-Devichi (1996) pp. 318-322.

12 Cfr. Dogliotti (1992) p. 1093.

13 Cfr. Cretney (1979) p. 491. Para el estudio del caso chileno vid. Cillero (1994) pp. 75-138. Por su parte, Lathrop sostiene que este principio se encuentra consagrado en todos los países que han llevado a cabo un proceso de reforma del Derecho de familia. Lathrop (2005) p. 33. Más concretamente, Acuña considera que el principio del interés superior del niño fue recogido legalmente en Chile por primera vez de modo expreso en el año 1998 con motivo de la Ley de filiación $\mathrm{n}^{\circ}$. 19.585, que estableció un trato igualitario entre todos los hijos cualquiera que fuera su origen. Se trataba de un imperativo, aclara la misma autora, que los instrumentos internacionales exigían adoptar en el ordenamiento interno. A partir de ahí, concluye la autora, ha pasado a ser un principio transversal en todas las materias de familia en que hay personas menores de edad involucradas, constituyéndose en la base de la fundamentación de las resoluciones judiciales respectivas. Acuña (2011) pp. 91-92. Por último, Rodríguez mantiene que el principio del interés superior del niño puede considerarse un principio vigente en la 
Regresando nuevamente al ámbito internacional, hemos de poner de manifiesto cómo la mencionada cláusula del interés superior del niño ha ido evolucionando, una vez adoptada por influencia de lo que venía ocurriendo en el Derecho de familia de determinados Estados, desde su embrionaria recepción en la Declaración de Ginebra $(1924)^{14}$, pasando por su mención formal en la Declaración de los Derechos del Niño (1959), hasta llegar finalmente a su definitiva eclosión en el texto de la Convención sobre los Derechos del Niño (1989) ${ }^{15}$.

El hecho de que la Convención de las Naciones Unidas sobre los Derechos del Niño se haya erigido en el eje vertebrador de todo el sistema contemporáneo de atención y protección de los derechos de la infancia y la adolescencia, no debe hacernos olvidar que han existido, incluso con anterioridad al propio texto convencional, y que continúan desarrollándose, diversos mecanismos internacionales de protección sectorial de los derechos y libertades de las personas menores de edad (ámbito laboral, administración de justicia, relaciones paterno-filiales, sustracción internacional de menores y adopción internacional, entre otros), en los que el principio del interés superior del niño ha ocupado un papel en igual medida relevante. Frente a la imposibilidad de recoger de forma exhaustiva, por exceder de las pretensiones del presente trabajo, todos los instrumentos internacionales existentes que directa o indirectamente se sustentan sobre este principio, sirva la presente selección de los más representativos como muestra significativa de su verdadera trascendencia ${ }^{16}$.

En el ámbito de la protección de personas menores de edad, el Convenio de La Haya sobre competencia de las autoridades y la ley aplicable en materia de protección de

legislación chilena desde la incorporación al ordenamiento de la Convención sobre los Derechos del Niño. Así, la Ley 19.585 de 1998 incorporó el principio al Código Civil chileno (artículos 222 inciso 2o, 225 inciso $3^{\circ}$ y 242 inciso $2^{\circ}$ ) y, con posterioridad a ella, el principio se expandió a diversas piezas de legislación (por ejemplo, el artículo 16 de la Ley de creación de los Tribunales de Familia). Rodríguez (2009) p. 566.

${ }_{14}$ Hay autores que en el Principio III de la Declaración de Ginebra (1924) creen ver una primera aproximación a la consideración primordial del interés del menor. Entre ellos, y a mero título ejemplificativo, GutiérRez y MarTí (2000) pp. 34-35, y Lázaro (2002) p. 99.

15 Tal y como expresa Aguilar, en el contexto del Derecho Internacional de los Derechos Humanos, la primera declaración que consagró los derechos de las personas menores de edad fue la Declaración de Ginebra sobre los Derechos del Niño, aprobada por la Sociedad de Naciones el 26 de diciembre de 1924. Posteriormente, prosigue el autor, el 10 de diciembre de 1948 la Asamblea General de las Naciones Unidas adoptó la Declaración Universal de Derechos Humanos que implícitamente incluía los derechos del niño. Más adelante, en 1959, ante la necesidad de una más directa protección de los derechos de las personas menores de edad en el mundo, la Asamblea General de las Naciones Unidas aprobó la Declaración Universal de los Derechos del Niño. Sin embargo, concluye el autor, dada la necesidad de contar con un instrumento normativo internacional, coercitivo y vinculante para los Estados partes y ya no tan solo con una Declaración, nace la Convención sobre los Derechos del Niño, adoptada y abierta a la firma y ratificación por la Asamblea General de las Naciones Unidas en su resolución 44/25, de 20 de noviembre de 1989, cuya efectiva entrada en vigor se produjo únicamente nueve meses después de su promulgación, el 2 de septiembre de 1990. Aguilar (2008) p. 227.

16 Apuntan Newell y Hodgkin que si bien el principio del interés superior del niño no aparece recogido como tal en el texto de ninguno de los dos Pactos Internacionales que desarrollan la Declaración Universal de los Derechos Humanos, el Comité de los Derechos Humanos (órgano colegiado llamado a fiscalizar la aplicación efectiva del Pacto Internacional de Derechos Civiles y Políticos de 1966) en dos de sus comentarios generales sobre la interpretación del mentado Tratado internacional, sí que ha entendido que el interés superior del niño es la consideración primordial (the paramount consideration) en los casos de separación y divorcio de los progenitores. Newell y Hodgkin (1998) pp. 38-39. 
menores, de 5 de octubre de 1961, establece, precisamente atendiendo al interés del menor, una excepción a la regla general, tanto en materia de atribución de competencias a las autoridades del lugar de residencia del menor, como al principio de aplicación de su ley interna (artículo 4) ${ }^{17}$. En temas de adopción internacional, el Convenio de La Haya relativo a la protección del niño y a la cooperación en materia de adopción internacional, de 29 de mayo de 1993, tiene por objeto "establecer garantías para que las adopciones internacionales tengan lugar en consideración al interés superior del niño y al respeto de los derechos fundamentales que le reconoce el Derecho internacional" (artículo 1) ${ }^{18}$. Por lo que al secuestro internacional de menores se refiere, no cabe duda de que en el ánimo de la Conferencia de La Haya estuvo siempre presente el objetivo de garantizar el interés del menor "secuestrado", extremo este que se evidencia en el propio Preámbulo del Convenio de La Haya, sobre aspectos civiles de la sustracción internacional de menores, de 25 de octubre de 1980, cuando en su primer párrafo se establece que "el interés del menor es de una importancia primordial para toda cuestión relativa a su guarda"19. Finalmente, en el ámbito de la administración de justicia y muy en particular a todo aquello referente a las personas menores de edad en conflicto con la ley penal, son de suma importancia las Reglas Mínimas de las Naciones Unidas para la Administración de la Justicia de Menores (Reglas Beijing), las Reglas de las Naciones Unidas para la Protección de los Menores Privados de Libertad y las Directrices de las Naciones Unidas para la Prevención de la Delincuencia Juvenil (Directrices de Riad), que recogen como principio básico y fundamental de actuación el del interés de todos los niños, niñas y adolescentes ${ }^{20}$.

Efectuado el apunte anterior, no por breve menos relevante, procedemos acto seguido al estudio de la configuración adoptada por la cláusula del interés superior del niño en dos de las disposiciones internacionales de mayor relevancia para el mundo de la infancia y la adolescencia: la Declaración Universal de los Derechos del Niño de 1959, y la Convención sobre los Derechos del Niño de 1989. El análisis de estos dos textos de las Naciones

17 Esta excepción opera en aquellos supuestos en que las autoridades del Estado del que es nacional el menor consideren que el interés de este así lo exige. En este sentido se pronuncian PérEz (2000) pp. 935-936; FERnÁndeZ (1998) pp. 439-442; y Adroher Biosca (1999) pp. 39-41.

18 Para un estudio más detallado de este concepto jurídico indeterminado en el contexto del Convenio de La Haya sobre la protección del niño y la cooperación en materia de adopción internacional, vid. GonZÁLEZ (1996) p. 313; Uhía (1998) pp. 1960-1965; de Mario (1999) pp. 1-8; Esplugues (1997) pp. 72-74; y GiméneZ-SaLinas (1998) pp. 27-28.

19 No obstante ser este uno de los tratados internacionales más extensos de los elaborados por la Conferencia de La Haya, con cuarenta y cinco artículos en total, solo se hace mención expresa al interés superior del menor en su Preámbulo; si bien es cierto que del trasfondo del artículo 13 del propio Convenio se infiere una referencia implícita al mismo. Una aproximación más detallada a la noción del interés superior del niño en relación con los secuestros internacionales de menores se encuentra recogida en Miralles (1989) pp. 93-98; y en Davis y Rosenblatt (1993) p. 28.

20 Aprobadas las dos primeras por la Resolución 40/33 de la Asamblea General, de 28 de noviembre de 1985 y la Resolución 45/113 de la Asamblea General, de 14 de diciembre de 1990, respectivamente. Estos textos señalan que el sistema judicial de menores debe hacer hincapié, respetar y fomentar el bienestar físico y mental de las personas menores de edad. Por su parte, las Directrices de Riad fueron adoptadas por la Resolución 45/112 de la Asamblea General, de 14 de diciembre de 1990, y contempla como principio y directriz de las políticas, medidas y programas preventivos de la delincuencia juvenil la protección del bienestar, el desarrollo, los derechos y los intereses de todos los niños, jóvenes y sus familias. 
Unidas debiera permitirnos llegar a entender de forma más precisa cuáles fueron las verdaderas razones que impulsaron al Comité de los Derechos del Niño a elaborar la Observación General nº. 14, así como los principales asuntos a los que el Comité trató de dar respuesta en el citado documento oficial.

\section{LA DECLARACIÓN UNIVERSAL DE LOS DERECHOS DEL NIÑO (1959)}

A nivel internacional, uno de los primeros textos en los que aparece formulado como tal el principio del interés superior del niño no es otro que el de la Declaración Universal de los Derechos del Niño ${ }^{21}$. Efectivamente, este concepto jurídico indeterminado aparece mentado en dos de los principios contenidos en este documento de las Naciones Unidas ${ }^{22}$, para ser más exactos en el segundo de ellos, relativo a los aspectos esenciales que deben tomarse en consideración al promulgarse leyes que garanticen el desarrollo físico, mental, moral, espiritual y social de las personas menores de edad; y en el séptimo, que eleva el interés superior del niño al nivel de elemento rector de quienes ostentan la responsabilidad de la educación y orientación de los niños, niñas y adolescentes ${ }^{23}$.

La amplitud con la que aparece recogido el principio del interés superior del niño en la Declaración de 1959 no es, ni por asomo, reflejo fidedigno de toda la extensión que esta cláusula pudo llegar a alcanzar y que de hecho obtuvo en las disposiciones de la ulterior Convención sobre los Derechos del Niño (1989).

Sin ir más lejos, el principio segundo de la Declaración de 1959 ha sido blanco de airadas críticas por buena parte de la doctrina internacionalista, al entender que limita la toma en consideración de la noción abstracta del interés superior del niño, tan solo a aquellos casos en los que los órganos legislativos deban valorar si las leyes que promulgan (es de suponer que también aquellas que enmiendan o derogan) benefician realmente a los niños, niñas y adolescentes por ellas afectados ${ }^{24}$. No se hace, por ende, alusión alguna a otros ámbitos en los que el citado principio también debiera ser tomado en consideración cuando se emprende cualquier tipo de medida o actuación que afecte, de manera directa o indirecta, a las persones menores de edad (actuaciones judiciales, administrativas o de instituciones privadas, entre otras).

21 El primer paso que dieron las Naciones Unidas para retomar los trabajos sobre protección de la infancia que ya habían sido emprendidos unos años antes por la Sociedad de Naciones, fue la constitución, en febrero de 1946, dentro del marco del Consejo Económico y Social, de una Comisión provisional de Asuntos Sociales (que posteriormente abandonaría el calificativo de provisional), integrada por representantes de países europeos y sudamericanos, todos ellos Estados parte originarios de las Naciones Unidas.

22 Para un comentario detallado de cada uno de los principios, diez en total, contenidos en la Declaración Universal de los Derechos del Niño vid. Melí́ (1989) pp. 2919-2924.

23 En el proyecto de Declaración librado por la Comisión de Asuntos Sociales del Comité Económico y Social no aparecía, en ninguno de sus principios, la cláusula del interés superior del menor, ni ninguna otra en un sentido similar. Tuvo que esperarse hasta el texto presentado por la Comisión de Derechos Humanos para encontrar por primera vez mencionado el concepto jurídico indeterminado del interés superior del menor. Más concretamente esta circunstancia se produjo en el principio tercero del proyecto, principio de nueva redacción que no aparecía en el texto anterior presentado por la Comisión de Asuntos Sociales, y que respondió al criterio planteado por Polonia.

24 Por todos vid. Longobardo (1991) pp. 386-387. 


\section{LA CONVENCIÓN SOBRE LOS DERECHOS DEL NIÑO (1989)}

\section{CONSIDERACIÓN DEL PRINCIPIO DEL INTERÉS SUPERIOR DEL NIÑO COMO PRINCIPIO RECTOR}

La Convención sobre los Derechos del Niño refleja una nueva perspectiva en torno a las personas menores de edad. Los niños, niñas y adolescentes dejan de ser vistos como propiedad intrínseca de sus progenitores, beneficiarios pasivos de una obra de caridad; para pasar a ser contemplados como plenos ciudadanos, destinatarios de sus propios derechos. La Convención, por tanto, ofrece un panorama en el que la persona menor de edad se caracteriza por ser un sujeto autónomo, integrante de una familia y de una comunidad, con derechos y responsabilidades adaptados a la etapa de desarrollo en la que se encuentra ${ }^{25}$.

Todos los derechos reconocidos al niño en el articulado de la Convención deben ser leídos e interpretados a la luz de cuatro valores fundamentales o principios rectores ${ }^{26}$ : el de igualdad, recogido en el artículo 2 de la Convención y formulado como de no discriminación; el del interés superior del niño, estipulado en el artículo 3 de la Convención; el del derecho a la vida, a la supervivencia y al desarrollo, contenido en el artículo 6 del propio texto internacional; $y$, finalmente, el del respeto a la opinión de la persona menor de edad, desarrollado en el artículo 12 de la Convención.

De los anteriores principios, si existe uno especialmente controvertido, ese es, precisamente, el relativo al interés superior del niño, no tanto por el proceso en sí que llevó a su establecimiento definitivo, sino porque la doctrina no parece estar en predisposición de alcanzar un acuerdo unánime acerca de su real significación ${ }^{27}$.

\section{Análisis jurídico del artículo 3, párrafo primero, de la Convención sobre los Derechos Del NiÑo \\ Para facilitar el curso de las explicaciones que a continuación se detallan, conside- ramos oportuno, en primer lugar, reproducir la literalidad del precepto objeto de nuestro}

\footnotetext{
${ }^{25}$ En palabras de Acuña, conforme al principio del interés superior del niño, la persona menor de edad es un sujeto de derechos, un titular autónomo de derechos distinto de sus progenitores, aun cuando su autonomía se encuentre en progreso y no esté plenamente desarrollada: el núcleo del principio y norma jurídica del interés del niño está, por consiguiente, en considerar que el niño, niña o adolescente es ante todo persona. ACuÑa (2011) p. 93.

${ }^{26}$ El Comité de los Derechos del Niño para conferir un mayor grado de homogeneidad al texto de la Convención sobre los Derechos del Niño redistribuyó en seis bloques el articulado del mencionado texto internacional. Esta estructura la encontramos desarrollada en CRC/C/GC/14, de 20 de noviembre de 1996, documento en el que se plasman las orientaciones generales respecto de la forma y el contenido de los informes que han de presentar los Estados partes con arreglo al apartado b) del párrafo primero del artículo 44 de la Convención. Siguiendo este modelo distributivo, el Comité destaca de entre todos los artículos del texto internacional cuatro de ellos y los posiciona en primer lugar considerándolos como principios generales informadores de todo el sistema.

${ }^{27}$ Alston lo califica como una disposición paraguas -it is an umbrella provision which prescribes the approach to be followed in all actions concerning children-. Precisamente por lo anterior, prosigue el autor, muy a menudo este principio es invocado conjuntamente con otros preceptos de la Convención. AlsTON (1996) p. 257. Esta misma idea es compartida por Cillero, al afirmar que la noción de interés superior contenida en el artículo 3 de la Convención sobre los Derechos del Niño apoya una interpretación holística del citado tratado internacional. Cillero (1999) p. 57.
} 
análisis, para, acto seguido, proceder al estudio minucioso de las particularidades que el mismo presenta: "En todas las medidas concernientes a los niños (children en la versión inglesa) que tomen las instituciones públicas o privadas de bienestar social, los tribunales, las autoridades administrativas o los órganos legislativos, una consideración primordial (a primary consideration) a que se atenderá será el interés superior del niño”.

\section{A. En qué casos debe ser tomado en consideración el principio del interés superior del niño}

El objetivo del artículo 3, párrafo 1, de la Convención sobre los Derechos del Niño, es velar porque el concepto jurídico indeterminado del interés superior del niño se observe en todas las decisiones y medidas relacionadas con las personas menores de edad. Esto significa que, en cualquier actuación o intervención que afecte a uno o varios niños, su interés superior deberá ser una consideración primordial a la que se atenderá preferentemente. La locución "medidas", contenida en el artículo de referencia, incluye no solo las decisiones finales, sino también todos los actos, conductas propuestas, servicios, procedimientos y demás iniciativas. Ello sin olvidar, que la pasividad o inactividad también están incorporadas a esta noción ${ }^{28}$.

Consecuentemente, la obligación jurídica contenida en el artículo 3, párrafo primero, de la Convención es de aplicación a todas las decisiones y medidas que afecten directa o indirectamente a los niños. Por tanto, la expresión, "concernientes a", debe ser entendida en un sentido amplio; refiriéndose, en primer lugar, a las medidas y decisiones relacionadas directamente con un niño, un grupo de niños o los niños en general y, en segundo término, a otros actos que repercutan en la infancia y la adolescencia, individual o colectivamente considerada, aunque la medida no vaya dirigida directamente a este colectivo poblacional.

Por último, destacar que el texto de la Convención alude de forma explícita a "todas las medidas concernientes a los niños", utilizando el plural "niños" (children en la versión inglesa) y no el singular "niño" (child en la versión inglesa). Tal circunstancia responde a que el precepto en cuestión pretende ofrecer una imagen global de la infancia, como un todo, y no centrarse en casos particulares. En definitiva, desde esta perspectiva, por tanto, el interés superior del niño se concibe tanto como un derecho colectivo como individual.

\section{B. A quién va dirigido el principio del interés superior del niño}

Otro aspecto relevante, digno de ser contemplado, es el referente a quién permanece obligado por el principio contenido en el párrafo primero del artículo 3 de la Convención sobre los Derechos del Niño. Si iniciamos la lectura del precepto en cuestión comprobaremos cómo la terminología utilizada ab initio, en particular el término "todas" (referido a todas las medidas concernientes a los niños), sugiere que cualquier individuo que actúe o adopte decisiones que afecten directa o indirectamente a los niños deberá atender a su interés superior. Ello incluiría, por tanto, a gobiernos, instituciones públicas o privadas, autoridades administrativas, tribunales, órganos legislativos y sujetos en particular (progenitores y tutores entre ellos). No obstante, si proseguimos con la iniciada lectura observaremos 
cómo, a continuación, el citado precepto incorpora una clara salvaguarda a tan amplia interpretación, al referirse expresamente a las medidas que adopten "las instituciones públicas o privadas de bienestar social, los tribunales, las autoridades administrativas o los órganos legislativos" 29 .

Una interpretación estricta de lo apuntado en el párrafo anterior nos conduciría a afirmar que el precepto objeto de nuestra atención está dirigido única y exclusivamente a las medidas de carácter oficial, así como a las acordadas por las instituciones privadas siempre que fueran, por supuesto, de bienestar social, dejando fuera de su órbita, en consecuencia, a los individuos en particular. En definitiva, la cuestión de fondo se centra en discernir si los progenitores y los tutores se encuentran o no obligados por el párrafo primero del artículo 3 de la Convención sobre los Derechos del Niño.

Para dar respuesta al interrogante planteado y averiguar el verdadero sentido conferido al texto de la disposición analizada debemos acudir nuevamente al seno del Grupo de Trabajo encargado de la elaboración del Proyecto de Convención. En este contexto, dos fueron las propuestas emitidas por los representantes de los Estados. Por un lado, aquellos partidarios de introducir una mención explícita a las personas encargadas de la guarda del menor (progenitores o guardadores en general); de otro, los que, por el contrario, defendían la no necesidad de su inclusión ${ }^{30}$.

La controversia se resolvió pacíficamente aceptando la segunda de las posturas (actitud estricta liderada por los Estados Unidos), es decir, la que contenía el listado más reducido de operadores sociales vinculados por la norma. Ello explica el porqué en la redacción definitiva del precepto no se contiene mención alguna a progenitores y guardadores. Ahora bien, de la propuesta norteamericana también se eliminó la restricción que la misma originariamente contenía a que el principio sería de aplicación únicamente a las "medidas oficiales".

En resumidas cuentas, a pesar de los arduos debates suscitados en el seno del Grupo de Trabajo, finalmente se adoptó el texto inicialmente propuesto por los EUA, suprimiendo el término "oficiales", y estableciendo que el principio del interés superior del niño afectaría a todas las medidas que tomen "las instituciones públicas o privadas de bienestar social, los tribunales, las autoridades administrativas o los órganos legislativos" ${ }^{\prime 1}$.

No obstante lo apuntado up supra, no cabe duda que uno de los aportes innegables de la Convención, y así lo reproduce, en idéntica medida, la Observación nº 14 (2013) del

29 Las instituciones privadas de bienestar social incluyen, sin lugar a dudas, a las organizaciones del sector privado (con o sin ánimo de lucro) que intervienen en la prestación de servicios esenciales para que los niños disfruten de sus derechos y que actúan como alternativa a los servicios públicos, en nombre de ellos, o junto con ellos. Para Acuña, el principio exige en su aplicación situar a las personas menores de edad, efectivamente, como centro de la preocupación legal, judicial, convencional y administrativa en dos dimensiones: una positiva, consistente en adoptar o acordar acciones o medidas en su beneficio; y, una negativa, que implica evitar riesgos o vulneraciones en las mismas medias o acuerdos. ACUÑA (2011) p. 93.

30 E/CN.4/L.1575, par. 23.

31 El Comité de los Derechos del Niño en su Observación general no. 14, sobre el derecho del niño a que su interés superior sea una consideración primordial, CRC/C/GC/14, de 29 de mayo de 2013, pág. 8, subraya que el término "tribunales" alude a todos los procedimientos judiciales, de cualquier instancia, ya estén integrados por jueces profesionales o personas que no lo sean, y todas las actuaciones conexas relacionadas con niños, sin restricción alguna; incluyéndose, por supuesto, los procesos de conciliación, mediación y arbitraje. 
Comité de los Derechos del Niño, ha sido la de extender la vigencia del principio garantista del interés superior del niño más allá del simple ámbito legislativo o judicial, ampliándolo a las actuaciones adoptadas por todo tipo de autoridades, instituciones privadas e incluso por progenitores o guardadores.

Efectivamente, el artículo 18 de la Convención, luego de reconocer el derecho y la responsabilidad de los progenitores en la crianza y la educación de sus hijos/as y el deber del Estado de promoverlo y garantizarlo, señala que los progenitores ejercerán sus funciones de acuerdo a una orientación fundamental: el interés superior del niño. En definitiva, los roles parentales no suponen una facultad absoluta -en el sentido de derecho/deber-, sino que por el contrario, se trata de derechos limitados en virtud del principio rector del interés superior del niño; prueba esta incontestable de que el artículo 18.1 de la Convención debe ser interpretado de forma sistemática con las previsiones dimanantes del artículo 3.1 del propio Tratado Internacional ${ }^{32}$.

\section{El interés superior del niño como "una" consideración o como "la" consideración primordial a que debe atenderse}

La discusión acerca de la redacción definitiva que debía ofrecer el párrafo primero del artículo 3 de la Convención sobre los Derechos del Niño se centró, básicamente, en la extensión que debía otorgarse a la expresión "consideración primordial" (primary consideration) y al verdadero alcance del artículo indeterminado "una" (a) que le precede ${ }^{33}$.

El borrador inicial presentado por Polonia establecía que "en todas las medidas relativas a los niños tomadas por sus progenitores, guardadores, instituciones sociales o estatales y, en particular, tribunales y autoridades administrativas, el interés superior del niño es la consideración primordial (the paramount consideration)". Apuntar, por tanto, que a tenor de la propuesta inicial polaca, el interés superior del niño debía ser la única y primordial consideración a tener en cuenta, por encima de cualquier otra circunstancia o pretensión que pudiera plantearse. El argumento utilizado para defender tal posicionamiento se basó en el hecho de que con esa redacción este artículo era perfectamente compatible con otros instrumentos internacionales ${ }^{34}$. Posteriormente, la delegación norteamericana propuso una

\footnotetext{
32 Para Orrego tanto la denominada "autoridad parental", referida a la persona del menor, como la "patria potestad”, referente a los bienes del menor, han de ser ejercitadas en función del interés de los menores, y no del interés de los progenitores. OrRego (2007) p. 219. Por su parte Díaz de Valdés, tras vincular el principio del interés superior del niño con la noción del bien común, afirma que tal relación ha sido recogida expresamente por el legislador chileno en el artículo 222 inciso $2^{\circ}$ del Código Civil, el cual obliga a los padres a procurar la "mayor realización espiritual y material posible" del niño como forma de servir a su interés superior. Díaz de VAldés (2010) p. 295. Finalmente, Rodríguez sostiene que en aquellos casos en que tanto los intereses de los padres como de los hijos sean igualmente legítimos, cabe ponerlos en jerarquía. En este supuesto, mantiene la autora, parece conveniente preferir el interés del niño, siendo a los progenitores a quienes corresponde sacrificar sus intereses personales en función del interés de sus hijos y no estos sacrificar el desarrollo armónico de su personalidad en función del interés de sus padres. Rodríguez (2009) p. 564.

33 Tal y como apuntan Newell y Hodgkin, la utilización del artículo indeterminado "la" (the en la versión inglesa) venía a significar que el interés del menor debía ser la única consideración a tener en cuenta. NEWELL y Hodgkin (1998) pp. 40-41. De esta misma opinión se manifiesta Puente (2001) p. 65.

34 A ello respondieron los representantes de los Estados que se oponían a tal redacción, liderados por los Estados Unidos, quienes entendían que esos otros instrumentos internacionales eran de aplicación a un
} 
sustancial variación en la original formulación del precepto, empleando la expresión "una consideración primordial (a primary consideration)"35. Esta segunda postura pretendía ofrecer una mayor flexibilidad en la aplicación del principio del interés superior del niño ${ }^{36}$ : no tanto por estimar que esta cláusula abstracta no fuera un principio digno de concentrar la mayor de nuestras atenciones, sino más bien porque entendieron que este principio debía ser "uno", eso sí de especial trascendencia, y no "el único" a valorar en aquellos supuestos en que los derechos de las personas menores de edad estuvieran implicados ${ }^{37}$.

Finalmente, la propuesta norteamericana fue la adoptada por el Grupo de Trabajo encargado de la redacción del texto de la Convención sobre los Derechos del Niño y la que posteriormente se incorporó a su redacción definitiva.

\section{SubJeTIVIDAd de la ClÁUSUla del INTERÉS SUPERIOR DEL NiÑo}

Una vez analizada detalladamente la forma en que se presenta, en términos generales, el principio del interés superior del niño en el articulado de la Convención sobre los Derechos del Niño, centramos nuestra atención, en última instancia, en cuál es el método escogido por el propio Tratado internacional, caso de pronunciarse al efecto, para dar contenido efectivo a este concepto jurídico indeterminado.

Lo cierto es que la Convención no define ni enumera indicador alguno que facilite la concreción práctica de esta cláusula abstracta del interés superior del niño, dejando su interpretación al buen hacer y juicio de la persona, institución u organización encargada de su aplicación; esencialmente las autoridades administrativas y los tribunales de justicia, ello sin olvidar a las instituciones privadas ${ }^{38}$.

conjunto más restringido de supuestos, tales como casos de custodia o adopción, respecto de los cuales no era difícil justificar una aproximación en la que el interés del menor predominase por encima de cualquier otra alegación o interés existente.

35 La propuesta de los Estados Unidos de América se pronunciaba del siguiente tenor literal: "en todas las medidas oficiales relativas a los menores, que tomen las instituciones públicas o privadas de bienestar social, tribunales de justicia o autoridades administrativas, el interés superior del menor será una consideración primordial".

36 Tal y como podemos evidenciar, entre la proposición inicial polaca y la posterior alternativa norteamericana existen dos importantes diferencias terminológicas. En primer lugar, y a pesar de que la traducción española de los vocablos "paramount" y "primary" sea esencialmente la misma: "primordial”, su extensión no es ciertamente idéntica; y, en segundo término, el ya comentado juego de los artículos determinado e indeterminado que le aporta mayor o menor extensión a la cláusula del interés superior.

37 Esta última postura, que fue la finalmente adoptada, y debido precisamente a la flexibilidad de la que hablábamos, entendemos que facultaría al encargado de determinar el interés superior del menor en un caso concreto, la libertad de poder considerar dicho interés como el único a tomar en consideración a tenor de las circunstancias existentes. Cosa muy distinta a entender que en absolutamente todos los supuestos el interés superior del menor deba ser el único contemplado. En este mismo sentido se pronuncian Newell y Hodgkin, afirmando que la propia Convención sobre los Derechos del Niño cuando hace mención a determinados niños que se encuentran en particulares circunstancias sí hace uso de la expresión "the best interests of the child shall be the paramount consideration", tomando como ejemplo paradigmático el artículo 21, relativo a la adopción, del propio texto convencional. Newell y HodgKin (1998) p. 272.

38 Aguilar apunta que el artículo 3 inciso $1^{\circ}$ de la Convención sobre los Derechos del Niño no esclarece lo que debe entenderse como el interés superior del niño. Si bien, en palabras del propio autor, la Convención sí hace referencia al citado principio en múltiples, ocho para ser más exactos, ocasiones, esto es, en el artículo 3 
Tal eventualidad ha sido fuertemente criticada por ciertos sectores de la doctrina especializada, que han señalado, entre otras circunstancias, la vaguedad e imprecisión con la que aparece formulado el término en el párrafo primero del artículo 3 del texto convencional ${ }^{39}$.

Esa indeterminación puede conducir, afirman esos autores, a soluciones o resultados tanto favorables a la autonomía del menor, a la plena consideración de sus derechos, como a un proteccionismo paternalista exacerbado, debido a que la decisión se deja en manos de las autoridades competentes sobre la materia (de los "decision makers" en su versión inglesa). En consecuencia, el concepto del interés superior puede ser utilizado tanto para reafirmar los derechos de los niños, niñas y adolescentes como para negarlos, y en ambos casos se hará en aras de la protección de la persona menor de edad.

No obstante, y aun admitiendo que el riesgo apuntado en el párrafo anterior es evidente, entendemos que el espíritu dimanante de la Convención no puede, bajo ningún concepto, ser ese. Así, la aplicación del principio del interés superior del niño a "todas" las medidas que le conciernan ha de ponerse irremediablemente en correlación con el reconocimiento por parte de la normativa internacional de los derechos de las personas menores de $\operatorname{edad}^{40}$.

\section{CONFIGURACIÓN DEL PRINCIPIO DEL INTERÉS SUPERIOR DEL NIÑO EN EL ORDENAMIENTO JURÍDICO CIVIL CHILENO}

\section{Marco general de ReFerencia}

Una vez expuesto el marco internacional de referencia que debe guiar los designios de los agentes sociales y jurídicos a la hora de definir y configurar en qué consiste el interés superior del niño, nos restaría únicamente por examinar cuál ha sido la técnica legislativa empleada por el Derecho civil chileno (extensible, sin lugar a dudas, a otras ramas del ordenamiento jurídico) para dar contenido en su ámbito doméstico al mentado principio general $^{41}$.

Al igual que acaece en otros sistemas jurídicos, el principio del interés superior del niño se presenta en Chile como un concepto jurídico indeterminado, que necesita pues ser concretado en cada situación específica ${ }^{42}$.

mencionado, y en los artículos 9.1, 9.3, 18, 20, 21,37, y en el 40, en ninguno de ellos se explica o define cuál es el verdadero significado de este concepto jurídico indeterminado. Aguilar (2008) p. 229.

39 En esta línea de pensamiento vid. Dogliotti (1992) p. 306; Buirette (1990) p. 73; Miralles (1989) pp. 532-533; Picontó Novales (1996) pp. 91-93; y Alonso (1997) pp. 23-24.

40 Cfr. Puente (2001) p. 66. En este mismo sentido se pronuncia Cillero, quien afirma que la aplicación del interés superior del niño debe primar sobre cualquier consideración cultural que pueda afectarlos, así como sobre cualquier otro cálculo de beneficio colectivo. Cillero (1996) p. 48.

41 Compartimos con Díaz de Valdés la idea de que ni los autores ni la jurisprudencia han elaborado una doctrina común sobre el tema. En realidad se ha escrito mucho más sobre las funciones del término, para qué podría servir, que sobre su contenido propiamente dicho. DÍAZ DE VALDÉs (2010) p. 292.

42 Lathrop sostiene que estamos ante un principio cuya definición se encuentra en desarrollo, o en otras palabras, que forma parte de los denominados conceptos indeterminados, relativos o abstractos, que adquieren verdadera dimensión cuando son aplicados al caso concreto. Lathrop (2005) p. 33. Por su parte, la Corte Suprema, en Willem Hekman con Orellana González (2014), apunta en su fundamento de Derecho décimo que "en materia de relación personal y directa de un menor ciertamente el énfasis está puesto en su interés superior"; y acto seguido aclara que "la terminología interés superior se enmarca en aquella clase de nociones 
En este sentido, la Corte Suprema, en Sentencia de 11 de abril de 2011, resume a la perfección la definición al uso que está siendo utilizada por la jurisprudencia chilena para identificar esta cláusula abstracta del interés superior del niño, al pronunciarse del siguiente tenor literal: "este principio -refiriéndose obviamente al del interés superior del niño- tiene directa relación con el pleno respeto de los derechos esenciales del niño, niña o adolescente, en procura del cabal ejercicio y protección de sus derechos esenciales y se identifica con la satisfacción plena de los derechos de los menores, en su calidad de personas y sujetos de derechos. Asimismo, constituye un elemento importante de interpretación como norma de resolución de conflictos jurídicos, permitiendo decidir así situaciones de colisión de derechos, según su contenido y la ponderación de los que se encuentran en pugna”.

Esta percepción fue ratificada unos años más tarde por la propia Corte Suprema, en Sentencia de 14 de enero de 2013. En esta ocasión, la Corte Suprema al referirse al principio del interés superior del niño lo hace identificando la citada cláusula general con los derechos del niño y del adolescente. De tal modo que al encontrarse presente y proyectarse en todo el sistema jurídico, al erigirse como una garantía de amplitud tal que obliga no solo al legislador sino que a todas las autoridades e instituciones y a los propios padres, interesa de sobre manera el aporte que tiene en el ámbito de la interpretación, al constituir una norma de resolución de conflictos jurídicos, permitiendo decidir así situaciones de colisión de derechos, según su contenido y la ponderación de los que se encuentran en pugna ${ }^{43}$.

Con la técnica del concepto jurídico indeterminado la Ley se refiere a una esfera de realidad cuyos límites no aparecen claramente precisados en su enunciado ${ }^{44}$, no obstante lo que sí está claro es que se pretende delimitar un supuesto concreto que admite ser precisado en el momento de su aplicación ${ }^{45}$. En otros términos, la norma no nos brinda la solu-

que la lingüística jurídica califica de abiertas, habida cuenta de su indescriptibilidad, que empuja a una definición funcional, siempre atenta y consecuente con la circunstancialidad casuística.

43 Para ser más exactos, la Corte Suprema en Herrera Porras con Gálvez Herrera (2013) manifiesta lo siguiente: "aun cuando su concepto sea indeterminado -en referencia al interés superior del menor-, puede afirmarse que el mismo, alude a asegurar el ejercicio y protección de los derechos fundamentales de los menores y a posibilitar la mayor satisfacción de todos los aspectos de su vida, orientados al desarrollo de su personalidad. Dicho principio se identifica con la satisfacción plena de sus derechos, en su calidad de personas y sujetos de estos, identificándose de esta manera interés superior con los derechos del niño y del adolescente". Casi idéntica conceptualización la encontramos en la sentencia de la Corte de Apelaciones de Concepción, Coronado Cea con Carrillo Maraboli (2013) y en la sentencia de la Corte de Apelaciones de Santiago, Heyner Mena con Capdeville Arrate (2012), en las que se estipula que "el interés superior del niño alude a asegurar al menor el ejercicio y protección de sus derechos fundamentales y a posibilitar la mayor suma de ventajas en todos los aspectos de su vida, en perspectiva de su autonomía y orientado a asegurar el libre desarrollo de su personalidad". El único aspecto novedoso que introducen estas últimas definiciones es la referencia expresa a la "autonomía" de las personas menores de edad.

${ }^{44}$ Dagnino manifiesta que al estudiar qué debe entenderse por interés del menor, ninguna norma lo explicita ni puede hacerlo satisfactoriamente, habida cuenta que toda previsión podría pecar, a priori, por exceso o por defecto, y que el interés del menor, globalmente considerado es la síntesis lógica de una amplia gama de componentes objetivos y subjetivos variables según las más diversas modalidades y circunstancias. DAGNino (1975) p. 1525.

45 Por el contrario, los conceptos determinados sí que delimitan de forma clara y precisa el ámbito de realidad al que se refieren. Por ejemplo la mayoría de edad se alcanza a los dieciocho años. 
ción directa de cada caso, de tal modo que esta debe ser inquirida acudiendo a criterios de valor o de experiencia, según la naturaleza del concepto.

Es evidente que la introducción de cláusulas generales en un ordenamiento jurídico acarrea sus ventajas e inconvenientes; entre los aspectos positivos podemos destacar la posibilidad que se ofrece al intérprete de acomodar las soluciones a los criterios de conciencia social prevalentes en cada momento histórico. Dicho de otra forma, permite la adaptación del mandato legal a cada supuesto concreto, atendiendo a la diversidad de sujetos y circunstancias que puedan presentarse, así como el mantenimiento de su validez a lo largo de un amplio período de tiempo, gracias a la posibilidad de ser leída de manera acorde con la evolución social y jurídica que se vaya produciendo. Entre los aspectos negativos, en cambio, evidenciar el problema que puede llegar a plantear una interpretación personal o subjetiva de la cláusula, que puede provocar desviaciones notables sobre aquello que la conciencia social considera aceptable en un momento determinado del tiempo ${ }^{46}$. Citar a modo de ejemplo lo suscrito por la Corte de Apelaciones de Antofagasta, de 6 de marzo de $2009^{47}$, en que se establece que "el interés superior del niño es uno que no puede constituirse legítimamente desde el interés de los jueces, sino cosa distinta, que se trata de un criterio primordial al que debe atenderse para decidir cosas en que hay niños y adolescentes involucrados, y que se constituye con su propia participación” ${ }^{48}$.

No obstante lo apuntado, y ante las serias dificultades para concretar en la práctica cuál es el verdadero significado del principio del interés superior del niño, parece que, durante los últimos años, la jurisprudencia, en primer lugar, y acto seguido el legislador chileno, han optado, siguiendo con ello una tendencia claramente de influencia anglosajona, por introducir ciertos indicadores o elementos de objetivación que faciliten al intérprete la comprensión y aplicación del concepto jurídico indeterminado objeto de nuestro análisis. Ello se viene realizando con la incorporación en el ordenamiento jurídico civil chileno de las llamadas, siguiendo la originaria denominación inglesa, statutory checklist o welfare checklist ${ }^{49}$.

\footnotetext{
46 Roca (1994) p. 975.

${ }^{47}$ Corte de Apelaciones de Antofagasta, Bravo Mujica con Liceo Experimental Artístico y de Aplicación (2009). En este supuesto de hecho se resolvió el caso de un estudiante al que no se permitió renovar su matrícula en el centro educativo por participar en actividades de carácter político y reivindicativo. Con posterioridad el caso llegó a la Corte Suprema, que resolvió en sentencia de 23 de abril de 2009.

48 Para un estudio detallado este caso vid. Lovera (2009) pp. 215-225.

49 Esta misma tendencia puede ser observada en otros ordenamientos jurídicos, tales como el español, donde la Sentencia del Tribunal Supremo, de 8 de octubre de 2009, tras recordar que el Código Civil español no contiene una lista de criterios que permitan al Juez determinar en cada caso concreto qué circunstancias deben ser tenidas en cuenta para justificar el interés del menor, lleva a cabo una relación de criterios que están siendo empleados, en los casos de atribución del cuidado personal de los hijos, para determinar qué resulta más beneficioso para ellos: "la práctica anterior de los progenitores en sus relaciones con el menor y sus aptitudes personales; los deseos manifestados por los menores competentes; el número de hijos; el cumplimiento por parte de los progenitores de sus deberes en relación con los hijos y el respeto mutuo en sus relaciones personales y con otras personas que convivan en el hogar familiar; los acuerdos adoptados por los progenitores; la ubicación de sus respectivos domicilios, horarios y actividades de unos y otros; el resultado de los informes exigidos legalmente $\mathrm{y}$, en definitiva, cualquier otro que permita a los menores una vida adecuada en una convivencia que forzosamente deberá ser más compleja que la que se lleva a cabo cuando los progenitores conviven".
} 
Buena muestra de ello podemos encontrarlo en la sentencia de la Corte Suprema, de 15 de julio de 2008, Rol 3.202-08, en que ya se contenía un intento de concreción de este concepto jurídico abstracto al fijar, en primer término, que "en estas materias -la controversia giraba en torno al ejercicio del cuidado personal de una persona menor de edad- cabe considerar siempre el interés superior del niño, principio fundamental en nuestro ordenamiento jurídico, tal y como dispone el artículo 16 de la Ley No 19.968 y, aun cuando su concepto sea indeterminado, como alusivo a asegurar el ejercicio y protección de los derechos fundamentales de los menores y a posibilitar la mayor satisfacción de todos los aspectos de su vida, orientados al desarrollo de su personalidad". En este mismo asunto, la Corte de Apelaciones de Valparaíso se había pronunciado con anterioridad, en fallo de 29 de abril de 2008, delimitando en mayor medida cuál era el interés superior del menor en el caso de autos. Así se entiende que "considerando que la menor se encuentra adaptada a su entorno familiar actual, a su medio escolar y social, trasladarla, por ahora de su ambiente puede ser perjudicial para su desarrollo emocional, puesto que, acostumbrada a un ambiente desde hace ya más de cinco años, su colegio, compañeros de estudios, actividades extraescolares, terapia psicológica, alterar eso, significaría sufrir un desarraigo de su entorno que podría perjudicarla más que serle beneficioso". Es por ello que la Corte de Apelaciones concluye que "no debe ser modificada la situación de la niña en cuanto a la tuición que detenta la abuela paterna, sino mantenerla aunque resulte penoso para los padres no tenerla en forma permanente en su hogar, por cuanto debe privilegiarse el interés superior del niño”.

Más clara aún es la sentencia de la Corte de Apelaciones de San Miguel, de 20 de noviembre de 2009. En el caso de autos se atribuye a un padre, por ser quien ostenta los recursos económicos, emocionales, psicológicos y sociales, el cuidado personal de sus dos hijos en detrimento de la madre, y el tribunal ad quem justifica su resolución, y he aquí lo interesante del presente supuesto de hecho, afirmando, en primer término que "debe tenerse en cuenta que el interés del menor constituye un concepto jurídico indeterminado, de contornos imprecisos y de profusa utilización en el derecho comparado"; para acto seguido proceder a un ejercicio de delimitación del principio en cuestión al manifestar que "no obstante, puede afirmarse que el principio del interés superior del niño alude a asegurar al menor el ejercicio y protección de sus derechos fundamentales; y a posibilitar la mayor suma de ventajas, en todos los aspectos de su vida, en perspectiva de su autonomía y orientado a asegurar el libre desarrollo de su personalidad; concepto, en todo caso, cuyos contornos deben delimitarse en concreto, en cada caso. En consecuencia, en cada caso que se somete a la decisión jurisdiccional un asunto de esta naturaleza, se deberá indagar cuál es el interés superior del niño, conforme a los siguientes factores: a) las necesidades materiales, educativas y emocionales de los niños y la probabilidad de que sean cubiertas por quien pretende la tuición; b) la capacidad y condiciones del solicitante para asumir la tuición; c) el efecto probable de cualquier cambio de situación en la vida actual de los menores; y d) si existiere algún daño sufrido o riesgo de sufrirlo por consecuencia de la tuición” ${ }^{50}$.

${ }^{50}$ Idénticos factores fueron los enumerados por la Corte de Apelaciones de Santiago, en Heyner Mena con Capdeville Arrate (2012). Por su parte, la Corte de Apelaciones de Concepción, en Coronado Cea con Carrillo Maraboli (2013), hizo especial mención a la particular consideración que debiera otorgársele a la opinión y 
Estos listados consisten en una simple enumeración de criterios llamados a facilitar la actuación de los tribunales cuando estos deban tomar una decisión amparados en el interés superior del niño. Tales indicadores, sin ir más lejos, aparecen contenidos en los artículos 225-2 y 229 del Código Civil, en redacción ofrecida tras la reforma introducida por la Ley 20.680, de 21 de junio de 2013, relativos al establecimiento del régimen y ejercicio del cuidado personal de los hijos y a la fijación del régimen de relación directa y regular con el progenitor que no tenga ese cuidado personal.

\section{Delimitación ENTRE las nOCiOneS: CONCEPTO JURídico INDETERMinado y DISCRECIONALIDAD}

Para delimitar con precisión el ámbito de aplicación de los conceptos jurídicos indeterminados resulta capital, según García de Enterría, distinguirlos del supuesto de aplicación de la libertad estimativa que comporta la discrecionalidad ${ }^{51}$.

Si lo propio de todo concepto jurídico indeterminado, en cualquier ámbito o sector del ordenamiento jurídico ${ }^{52}$, es que la imprecisión de su enunciado no se traduce en una indeterminación de sus aplicaciones, es decir, que su uso solo admite una única solución justa, a la que se arriba mediante una actividad de cognición, objetivable por tanto, y no de volición, ello no es así, en cambio, en el ejercicio de una potestad discrecional que permite, por el contrario, una pluralidad de soluciones, llamémosle justas, o, en otros términos, optar entre diversas alternativas que son igualmente equitativas desde la perspectiva del Derecho.

La discrecionalidad, tal y como acabamos de apuntar, es esencialmente una facultad de elección entre varias opciones igualmente justas, porque la decisión se fundamenta normalmente en criterios extrajurídicos (de oportunidad, económicos), no incluidos en la Ley y remitidos al juicio subjetivo de la Administración. A contrario sensu, la aplicación de conceptos jurídicos indeterminados es un caso de aplicación de la Ley, puesto que se trata de subsumir en una categoría legal (configurada eso sí de una manera amplia y flexible) unas circunstancias reales determinadas (estamos, por ende, ante un proceso reglado). Así, el concepto del interés superior del niño se configura por el sistema normativo de tal forma que únicamente se da una única solución justa en la concreción del mismo en cada una de

\footnotetext{
sentimientos expresados por las personas menores de edad, en especial cuando se trata de concretar que deba entenderse por su interés superior. Así, en su considerando sexto se establece que "el derecho del niño a ser oído, no se restringe únicamente a un plano procesal, adquiriendo naturaleza de derecho humano. Guarda relación con el derecho que posee todo menor de edad a manifestar su opinión en los diversos ámbitos de su vida: familiar, social, escolar, etc.; y que dicha opinión sea considerada, tomando en cuenta la capacidad que pudiere tener para formarse un juicio propio sobre el asunto que le atañe".

51 Cfr. García de Enterría y Fernández (1962) p. 171.

52 La técnica de los conceptos jurídicos indeterminados se da en todas las ramas del ordenamiento jurídico. En el Derecho civil (buena fe, diligencia de un buen padre de familia, negligencia, interés superior del niño, interés de la familia, entre otros), en el Derecho penal (nocturnidad, alevosía, abusos deshonestos, por citar algunos), en el Derecho procesal (división de la continencia de la causa, conexión directa, pertenencia y relevancia de las pruebas, medidas adecuadas para promover la ejecución, perjuicio de reparación imposible o difícil y más), en el Derecho mercantil (interés social, diligencia del buen comerciante, sobreseimiento general en los pagos, entre los muchos existentes).
} 
las circunstancias de hecho en que sea de aplicación ${ }^{53}$. El encargado de precisar ese interés (progenitores, jueces, equipos sanitarios, administración) no va a ser libre para decidir, a través de un proceso volitivo de discrecionalidad, entre varios posibles intereses, sino que se tendrá que precisar el interés que real y efectivamente sea el verdadero y adecuado para cada supuesto de hecho.

\section{Estructura interna de todo CONCEPTO JURídico INDETERMinAdo: EN PARTICULAR, EL INTERÉS SUPERIOR DEL NIÑO}

En la estructura de todo concepto jurídico indeterminado, y por ende también en la noción abstracta del interés superior del niño, siguiendo lo establecido por la doctrina germana son perfectamente reconocibles tres niveles de concreción: a) un núcleo fijo o "zona de certeza positiva", configurado por datos previos y seguros a modo de presupuesto o condicionamiento inicial mínimo; b) una zona intermedia o de incertidumbre o "halo del concepto", más o menos definido, donde caben varias opciones dentro de márgenes relativos e imprecisos y, finalmente; c) una "zona de certeza negativa", también segura en cuanto a la exclusión del concepto ${ }^{54}$.

Si aplicamos la anterior teoría a la cláusula general a la que venimos dedicando toda nuestra atención, arribaremos, de forma evidente, a la siguiente conclusión ${ }^{55}$ : la zona de certeza positiva del interés superior del niño radica en la circunstancia de que a la persona menor de edad le interesa, ante todo, preservar su integridad física y moral, así como garantizar el desarrollo integral de su personalidad (condicionante absolutamente mínimo según las estimaciones comunes); por lo que a la zona de imprecisión (halo del concepto) se refiere, esta daría pie a diversas posibilidades. Así, por ejemplo, en un caso de atribución del cuidado personal de un menor, cabría atribuir ese cuidado a su padre o a su madre si ambos presentaran buenas condiciones para atenderlo, en igual medida sucedería a la hora de decidir la extensión de un régimen de relacionamiento a favor del progenitor no custodio, de los abuelos o de otros parientes (solo festivos, una vez al mes, con o sin pernoctaciones, y múltiples posibilidades más). Como podemos comprobar en este segundo nivel se requiere de una estimación o juicio de valor, tanto más amplia a medida que el

53 Para Sainz, la utilización de tales conceptos por una norma no significa, por sí sola, la atribución de la facultad de elegir discrecionalmente entre varias soluciones posibles aquella que en cada caso se considera conveniente u oportuna; esta tesis, por el contrario, mantiene que la interpretación y aplicación de todo concepto jurídico, cualquiera que sea el grado de su indeterminación, no admite, si la norma no dispone otra cosa, más que una solución correcta y que, por tanto, la corrección de la decisión que se tome puede ser controlada judicialmente sin que tal control implique una mera sustitución de criterios, sino el resultado de la búsqueda de la solución justa. SAINZ (1996) p. 192.

54 Cfr. Rivero (2007) p. 192. También se hace eco de esta estructura Rodríguez (2009) pp. 568-569.

55 Miralles realiza la misma operación, aplicando la noción de concepto jurídico indeterminado al interés superior del menor tal y como aparece configurado en el Convenio de La Haya sobre aspectos civiles del secuestro internacional de menores, de 25 de octubre de 1980. Para este autor, el núcleo o "zona de certeza" residiría en la propuesta de solución convencional a los secuestros, es decir, en la protección de los derechos de guarda y visita mediante el retorno del menor secuestrado; la zona intermedia o "halo de incertidumbre" estaría configurada por las circunstancias que concurran en el caso concreto de que se trate; y, por último, la "zona de certeza negativa" habría que situarla en el hecho de que todo secuestro es, prima facie, negativo para el desarrollo del menor. Miralles (1989) pp. 97-98 
concepto deja de ser técnico o especializado y se inserta en lo cultural o valorativo ${ }^{56}$; por último, la zona de certeza negativa, haría referencia al punto o margen a partir del cual desaparece el valor implícito en el concepto, en nuestro caso deja de haber "interés del menor”. Prosiguiendo con los ejemplos anteriores, diríamos que un niño, niña o adolescente no puede ser confiado a un sujeto depravado o violento, o no puede concederse un régimen de visitas a un padre/madre que ha sido condenado por abusar sexualmente de su hijo/a menor de edad.

Supuesta la anterior estructura, se hace evidente que la dificultad a la hora de precisar en qué consiste el interés del menor no la encontramos ni en la zona de certeza positiva ni en la zona de certeza negativa, sino que será justamente en la zona intermedia, en esa zona de imprecisión, en la que residirá la complejidad de elección y decisión ${ }^{57}$.

Hay luego, otra dificultad específica, propia de la aplicación de las normas que incorporan conceptos jurídicos indeterminados y que ha retratado a la perfección Martín ${ }^{58}$. Si cuando se trata de conceptos determinados (recordar el ejemplo citado en páginas anteriores de la mayoría de edad que se obtiene a los dieciocho años) basta la constatación del dato vinculado al concepto (la fecha de nacimiento) para la aplicación del mismo y la producción del efecto jurídico, en los conceptos indeterminados se exige, por parte de la persona u órgano que ha de llevarlo a la práctica, una doble labor: precisar el significado y contenido del concepto (qué es o en qué consiste el interés del menor), y después, comprobar en qué situación y circunstancias concretas de las posibles se da el valor que ha pretendido captar la norma (lo que más conviene a un niño determinado) y sobre todo dando una relevancia inusitada a los datos y circunstancias del caso concreto, porque estos son los que van a permitir encontrar la solución dentro del ámbito de apreciación o zona de variabilidad del concepto jurídico indeterminado. En definitiva, en los del primer tipo (los determinados) la especificación del significado y contenido la hace la ley; en el segundo (los indeterminados) se hace en el preciso instante de su aplicación.

Finalmente, resulta interesante destacar que la autoridad judicial se encuentra legitimada para fiscalizar la aplicación de los conceptos jurídicos indeterminados, valorando si la solución que con ella se ha alcanzado es la única respuesta justa que la ley permite. Así, con

\footnotetext{
56 Es conveniente recordar en este punto, para facilitar la comprensión de la terminología empleada, apuntar que hay conceptos jurídicos indeterminados que incorporan nociones de experiencia (incapacidad para el ejercicio de sus funciones, premeditación, fuerza irresistible), que se ventilan en la apreciación de los hechos; mientras que otros, en cambio, son conceptos de valor (implican juicios de valor), ya sean técnicos (impacto medioambiental, por ejemplo) o valorativos (buena fe, estándar de conducta del buen padre de familia, interés público).

57 En esa aplicación "in concreto" de la norma es donde reside el margen de movilidad del juez, individuo o autoridad administrativa que decide. En este sentido, Miralles añade que cuantos más elementos de concreción facilite la norma abstracta, menos riesgos de atentado habrá respecto a la libertad de apreciación de la autoridad que la aplica y en cuanto a la seguridad jurídica que ha de presidir todo procedimiento. Miralles (1989) p. 96. 58 Cfr. Martín González (1967) pp. 286-292. En un sentido similar se pronuncia Rivero (2007) pp. 193194. Por su parte, Sainz afirma que con la técnica del concepto jurídico indeterminado aplicada al interés superior del niño no se atribuye al juez una pura autorización para decidir según su concepción personal de la justicia, sino que por el contrario, se le obliga a aplicar el concepto conforme a su verdadero sentido (núcleo del concepto), pero dentro de los márgenes que el mismo ofrece (halo del concepto). SAINZ (1976) p. 197.
} 
su enjuiciamiento el juez se limita a reducir la «zona de incertidumbre», reconduciendo el caso concreto a una de las dos zonas de certeza, la positiva o la negativa ${ }^{59}$.

Debemos destacar también, como acertadamente hace Orrego, que, siendo el interés superior del niño un principio fundamental de nuestra legislación civil, la autoridad judicial llamada a resolver una controversia que lo involucre, no puede obviar la aplicación de este criterio orientador, ni preterir su valoración hasta el momento final de redacción de la sentencia. Lo anterior puede sostenerse, aun en aquellos casos en que no existiere una norma específica que resolviere el litigio, pues estando ante un principio general del derecho, hemos de entender que forma parte inherente de lo que el artículo 24 del Código Civil califica como de "espíritu general de la legislación”. Aun es más, este principio debe considerarse en igual medida como regla moderadora e inspiradora de las actuaciones judiciales encaminadas a cubrir, empleando el criterio de la equidad, las lagunas legales que el sistema pudiere presentar, de acuerdo con lo prescrito en el artículo 170, número 5, del Código de Procedimiento Civil ${ }^{60}$.

Es precisamente por todas esas dificultades de aplicación y determinación que hemos constatado que presenta la utilización por parte de un sistema normativo (entre ellos el chileno) de los conceptos jurídicos indeterminados, que gran parte de la doctrina ha manifestado serias dudas acerca de la virtualidad práctica del principio general del interés superior del niño ${ }^{61}$.

59 García de Enterría al hablar de la fiscalización jurisdiccional de los conceptos jurídicos indeterminados manifiesta la necesidad de reservar a la autoridad que aplica un concepto jurídico indeterminado el llamado "margen de apreciación", que en todo caso es un margen cognoscitivo y no volitivo; este margen de apreciación será mayor o menor ordinariamente según la posibilidad o no de aportar o presentar ante el Tribunal la totalidad de los elementos de hecho que la autoridad que aplicó el concepto tuvo en cuenta. GarCía dE EnTERría (1962) p. 174. De acuerdo con estos planteamientos se encuentra Martín, al decirnos que cuando se aplican los conceptos jurídicos indeterminados a los casos concretos, nos encontramos ante una actividad de aplicación e interpretación del único sentido de la norma, y en cuanto tal, fiscalizable. MarTín (1967) pp. 279-280.

60 Orrego (2007) p. 14.

${ }^{61}$ Desper se pregunta cómo un tribunal se halla en la posición determinar con certeza aquello que constituya el interés superior del niño. La propia autora responde a su pregunta y afirma que la anterior es una cuestión muy compleja, sujeta a una gama infinita de casos individuales y a la fluidez de la vida humana que hace que no pueda encontrarse la respuesta en una norma. DesPer (1957) pp. 169-170. Por su parte, Dogliotti nos recuerda que uno de los peligros que puede implicar el uso de una noción abstracta como la nuestra es la creación por parte de los tribunales de "cómodos automatismos" que desvirtúen su verdadero sentido. DogLiotTi (1992) p. 1099. Asimismo, Bromley subraya la excesiva apertura e indeterminación de dicho principio, lo que hace inevitable que a la hora de su aplicación las decisiones concretas se basen, en buena medida, en las convicciones y predilecciones personales de los jueces. BROMLEY (1987) p. 332. Además, Cretney al tratar en su obra sobre el welfare principle (principio del bienestar) subraya la objeción, que él no comparte, de que el mentado principio aporta poco para tratar de definir y explicar su proceso de aplicación. Cretney (1979) p. 499. Por su parte, Alonso en su estudio sobre la Ley Orgánica Española 1/996, de 15 de enero, de protección jurídica del menor es meridianamente claro al manifestar que seguimos sin saber que es el interés superior del niño. Alonso (1997) p. 23. Por último, Gómez de la Torre se atreve a precisar que el interés del niño llevado a la práctica se manifiesta en las siguientes materializaciones: permitirle la indagación de su filiación cuando esta no esté legalmente determinada; garantizarle el ejercicio de los derechos que surgen de su calidad de persona; permitirle manifestar su opinión en todas las instancias judiciales o extrajudiciales en que este tenga interés; facilitar su intervención en los procesos de separación o divorcio de sus progenitores; guiar e inspirar todos los procesos de adopción y, en particular, tomar en consideración la opinión del adoptando cuando su edad y madurez así lo permitan. GÓmez de LA TORRe (2000) pp. 25-26. 


\section{Hacia Una objetivación del Sistema}

Tal y como ya avanzamos en apartados anteriores, frente a la inconcreción existente en esta materia en el sistema normativo chileno, que como hemos puesto de relieve se limitaba a reproducir en sus disposiciones jurídicas la ya célebre cláusula general del interés superior del niño ${ }^{62}$, nuestro legislador, siguiendo la técnica prototípica de los ordenamientos jurídicos anglosajones, parece haber optado por incorporar, junto con enunciados legales del tipo cláusula general, un elenco de criterios indicativos que pretenden especificar y facilitar la búsqueda del interés de la persona menor de edad, criterios que vendrían a reflejar lo que la sociedad considera en cada momento como los factores más importantes o relevantes a la hora de definir lo que significa el interés de los niños y las niñas.

Con este planteamiento y técnica, en el fondo mixta, en los artículos 225-2 y 229 del Código Civil, en redacción ofrecida tras la reforma introducida por la Ley 20.680, de 21 de junio de 2013, se enumeran, para casos y situaciones específicas -en particular para la asignación del cuidado personal de los hijos tras las crisis matrimoniales y, como consecuencia, para la fijación del régimen de relación directa y regular con el progenitor no custodio-, un elenco de indicadores que nos acercan a la determinación de qué debe considerarse como el interés del menor. Su interpretación y aplicación queda, como es lógico, en manos de los tribunales, cuyo margen de actuación será, en todo caso, más restringido.

En definitiva, se trata de identificarlo por medio de una lista de situaciones que quedan incluidas en el concepto general del interés del menor, equiparando el concepto de interés con la finalidad de proporcionar al Juez una guía en el momento de tomar decisiones que afecten a la persona menor de edad.

Uno de los principales reproches que recae sobre este sistema de objetivación del interés del menor apunta a que provoca o puede generar una rigidez excesiva, ya que una construcción jurídica que tenga como base la previsión de todas y cada una de las situaciones en que puede encontrarse el menor es peligrosa, en tanto que puede dejar fuera situaciones impensables en el momento en que se redacta el precepto; riesgo este, no obstante que queda superado con una cláusula de cierre abierta que de cabida a cualquier nueva circunstancia que pueda ir surgiendo.

Comentarios críticos al margen, procedemos a continuación a detallar con brevedad algunos de los aspectos más destacables de los indicadores contenidos en los artículos 225-

\footnotetext{
${ }^{62}$ El principio del interés superior del menor es el criterio a que debe ajustarse el Juez para adoptar cualquier tipo de decisión que afecte directa o indirectamente a los hijos; así lo reiteran diversas disposiciones legales chilenas. En este sentido se pronuncia el artículo 242 inc. $2^{\circ}$ del Código Civil al preceptuar que "para adoptar sus resoluciones el Juez atenderá, como consideración primordial, al interés superior del hijo, y tendrá debidamente en cuenta sus opiniones, en función de su edad y madurez". En semejantes términos es recogido por la Ley de Tribunales de Familia en su artículo 16 inc. $2^{\circ}$, al fijar que "el interés superior del niño, niña o adolescente, y su derecho a ser oído, son principios rectores que el Juez de familia debe tener siempre como consideración principal en la resolución del asunto sometido a su conocimiento". En el proceso matrimonial sucede igual: "Las materias de familia reguladas por esta Ley deberán ser resueltas cuidando proteger siempre el interés superior de los hijos" (artículo 3, inc. 10 de la Ley de Matrimonio Civil); "Cuando existieren menores de edad comprometidos, el Juez deberá considerar especialmente el interés superior del niño" (artículo 85 inc. $2^{\circ}$ de la Ley de Matrimonio Civil).
} 
2 y 229 del Código Civil, que han venido a positivar una tendencia ya iniciada hace unos años por la jurisprudencia tanto nacional como internacional.

Así, tanto en el establecimiento del régimen y ejercicio del cuidado personal, como en la determinación del régimen de relación directa y regular con el progenitor que no tenga el cuidado personal del hijo, los padres, o el Juez en su caso, deberán atender al interés superior del menor, considerándose y ponderándose, especialmente, una serie de criterios y circunstancias delimitados por la norma ${ }^{63}$.

En primer lugar, deberá tenerse en particular consideración la opinión y los sentimientos expresados por el hijo, teniendo en cuenta su edad y su capacidad de discernimiento (artículo 225-2, apartado f y 229 inc. 1º, ambos del Código Civil): no es tarea fácil averiguar cuáles son los verdaderos deseos de un niño, niña o adolescente y una vez conocidos estos sopesar la importancia que debe otorgárseles. Así, por ejemplo, en algunos casos el punto de vista manifestado por la persona menor de edad puede haber sido objeto de manipulación por parte de alguno de sus progenitores; en otros, aun sin darse esa mediatización de sus palabras, sus anhelos pueden ser claramente contrarios o contraproducentes a sus verdaderas necesidades. Lo que sí es claro es que la ley reconoce como una de las más relevantes manifestaciones del principio del interés superior del menor, el deber del Juez de oír a los hijos, que se concreta con el derecho de audiencia de los mismos ${ }^{64}$.

${ }^{63}$ La propia Corte Interamericana de Derechos Humanos en el Caso Forneron e Hija Vs. Argentina, sentencia de 27 de abril de 2012, estableció que "la determinación del interés superior del niño, en casos de cuidado y custodia de menores de edad se debe hacer a partir de la evaluación de los comportamientos parentales específicos y su impacto negativo en el bienestar y desarrollo del niño según el caso, los daños o riesgos reales, probados y no especulativos o imaginarios, en el bienestar del niño. Por tanto, no pueden ser admisibles las especulaciones, presunciones, estereotipos o consideraciones generalizadas sobre características personales de los padres o preferencias culturales respecto de ciertos conceptos tradicionales de la familia. Asimismo, unos meses antes, la Corte Interamericana de Derechos Humanos, en el Caso Atala Riffo y niñas Vs. Chile, sentencia de 24 de febrero de 2012, se había pronunciado en términos muy similares.

${ }^{64}$ Una interesante valoración del derecho de audiencia de la persona menor de edad se encuentra en la sentencia de la Corte Suprema, Martínez Vicencio con Pávez Cáceres (2014). En este supuesto de hecho un padre, con base en el artículo 225 del Código Civil, reclama el cuidado personal de su hijo adolescente que se encuentra residiendo con él en casa de los abuelos paternos. Tal petición es rechazada tanto, en primera instancia, por el Juzgado de Familia de Villa Alemana, como por la Corte de Apelaciones de Valparaíso. En lo que ahora nos interesa, el adolescente, en audiencia confidencial, manifestó su deseo de permanecer junto a su progenitor, sin embargo el fallo impugnado desestimó su opinión afirmando que "el menor por una situación geográfica quería permanecer con su padre", lo que -a juicio del tribunal ad quo- denotaba una falta de rigurosidad y profundidad en la indagación que se hizo en la citada audiencia, por no ser ese el único factor a ser tomado en consideración. Ante tal circunstancia, la Corte Suprema tras manifestar que "ha de tenerse en consideración el interés del adolescente como principio fundamental e inspirador de nuestro ordenamiento jurídico, de relevancia transversal en la legislación de familia y de menores", entiende que, en el presente caso, el referido concepto jurídico indeterminado se relaciona con dos aspectos esenciales, "por un lado, con el permitir que el hijo adolescente se desarrolle dentro de un entorno conocido y aceptado por él y, por otro, se refiere al respeto de su autonomía progresiva". La Corte Suprema concluye afirmando que ninguno de esos dos puntos fue debidamente atendido por los jueces del grado, puesto que su decisión desatendió la situación real en la que se encontraba el adolescente, "esto es, que subida hasta ahora, se ha desarrollado en la ciudad de Villa Alemana, lugar donde concurre al colegio y tiene su red social, por lo que resolver entregar su cuidado personal a su madre, significaría disponer de un cambio sustancial en su vida, que involucra incluso radicarse en otra ciudad, todo lo cual trae consigo necesariamente alteraciones y adaptaciones, que si ya para un adulto son difíciles de sobrellevar, con mayor razón lo será para un adolescente, más aún si se tiene presente su resistencia 
Un antes y un después en el derecho de audiencia de las personas menores de edad viene marcado por el Caso Atala Riffo y niñas Vs. Chile, en el que la Corte Interamericana de Derechos Humanos, en sentencia de 24 de febrero de 2012, concluye que la sentencia de la Corte Suprema de Justicia chilena violó el derecho de las niñas a ser oídas consagrado en el artículo 8.1, en relación con los artículos 19 y 1.1 de la Convención Americana sobre Derechos Humanos, ya que la Corte Suprema no había explicado en su resolución cómo evaluó o tomó en cuenta las declaraciones y preferencias hechas por las menores de edad que constaban en el expediente.

En efecto, la Corte Interamericana constató que la Corte Suprema chilena no adoptó una decisión en la que razonara sobre la relevancia atribuida por dicho órgano judicial a las preferencias de convivencia expresadas por las menores de edad y los motivos por los cuales se apartaba de su voluntad. Por el contrario, la Corte Suprema se limitó a fundamentar su decisión en el supuesto interés superior de las tres menores de edad, pero sin motivar la razón por la que consideraba legítimo contradecir la voluntad expresada por las niñas durante el proceso de tuición, teniendo en cuenta el estrecho vínculo existente entre el derecho de los niños, niñas y adolescentes a ser oídos y el objetivo de dar contenido al principio del interés superior del niño ${ }^{65}$.

En segundo término, también deben valorarse las necesidades materiales, educativas y emocionales que el niño, niña o adolescente pueda presentar (artículo 225-2, apartado b, del Código Civil). Como podemos comprobar se incluyen en este apartado tanto las necesidades más perentorias - entendidas como el alojamiento, la manutención, el vestido, entre otras- como las de carácter moral del niño -tales como su estabilidad emocional o el adecuado desarrollo integral de su personalidad-. Por lo que a las primeras se refiere, es sumamente complejo valorar la importancia que los tribunales les dispensan. De esta forma, a no ser que se produzca un gran desequilibrio en la situación económica de la que gozan los progenitores, su importancia o incidencia es relativa. Dentro de esos aspectos materiales es al tema de la vivienda al que se le concede un mayor énfasis, entendida esta no solo en términos físicos, sino también como hogar, habida cuenta al tiempo y cuidados que los progenitores procuran al menor (lo que los anglosajones denominarían el "day-to-day care"). Por su parte, las necesidades de índole más emocional o espiritual suelen estar estrechamente vinculadas con la edad y personalidad de la persona menor de edad, y tienen un carácter marcadamente subjetivo, lo que hace que los Tribunales, irremediablemente, deban ayudarse del asesoramiento de peritos para su mejor delimitación. Por último, las necesidades educativas pueden ser interpretadas, entendemos, en un doble sentido: amplio, que englo-

al cambio, tal como lo manifestó en su oportunidad y que atendida su edad, no es posible pasar por alto, salvo que existan antecedentes que permitan concluir que con ello no se resguarda debidamente su interés superior, lo que, conforme al mérito de los antecedentes no se advierte".

65 Los hechos de este caso se relacionan con el proceso de custodia o tuición que fue interpuesto ante los tribunales chilenos por el padre de tres niñas en contra de la señora Karen Atala Riffo, madre de las mismas, por considerar que su orientación sexual y su convivencia con una pareja del mismo sexo producirían un daño irreparable a las menores de edad. En este sentido, la Corte tuvo que resolver, entre otros elementos, la responsabilidad internacional del Estado por el alegado trato discriminatorio y la interferencia arbitraria en la vida privada y familiar que había sufrido la señora Atala debido a su orientación sexual en el proceso judicial que resultó en el retiro del cuidado y custodia de sus hijas. 
baría prácticamente todo lo relacionado con la crianza de una persona menor de edad -debido a su extensión son pocos los casos en que estas necesidades educativas, entendidas en este primer sentido, se han mostrado como decisivas-; o más restringido, limitando en este caso a la noción de educational schooling, es decir, a la estabilidad educativa del niño, niña o adolescente. En esta segunda acepción del término, sí que pueden este tipo de necesidades llegar a ser un elemento relevante o trascendental. Pensemos, por ejemplo, en un progenitor que con el curso ya iniciado decide trasladar su residencia a otro lugar.

Asimismo, no podemos obviar la importancia de tratar de mantener el denominado "statu quo" de la persona menor de edad. Es decir, preservar al máximo la estabilidad personal y emocional que cualquier cambio, en este caso derivado de una ruptura familiar, pueda generar en los niños, niñas y adolescentes (artículo 225-2, apartados d e i del Código Civil). Los Tribunales son muy reacios a separar a un/a niño/a de aquel progenitor con el que hayan venido conviviendo, salvo que existan poderosas razones para hacerlo o los trastornos que ello suponga para la vida del menor sean mínimos - por ejemplo, siga acudiendo al mismo centro educativo, pueda mantener sus amistades, vivir en el mismo entorno ${ }^{66}$-. Para determinar cuál es el "statu quo" de una persona menor de edad, los Tribunales deben examinar toda la historia vital de ese niño, niña o adolescente y no tan solo su posición en el momento inmediatamente anterior al inicio del proceso (artículo 225-2, apartado e del Código Civil). Un ejemplo que viene a ilustrar este comentario lo encontramos en la sentencia de la Corte Suprema, de 13 de febrero de 2014, Rol 10358-2013 ${ }^{67}$. En este caso, de la simple lectura de los hechos acaecidos se constata que el interés de la niña implicada ha sido vulnerado reiteradamente en un aspecto fundamental, la niña está próxima a cumplir siete años y en ese corto período de su vida, ya sea por decisiones de los Tribunales o acuerdo de sus progenitores, ha debido cambiar cinco veces de residencia, lo que se ve agravado, ya que no únicamente cambia de progenitor sino que, también, de ciudad, de colegio, y por ende de contexto de socialización. Ante tales circunstancias la Corte Suprema, enten-

66 Eekelaar (1992) pp. 227-228, nos ofrece una evidencia empírica de que en los Tribunales ingleses son partidarios de no modificar las circunstancias y condiciones en que ha venido creciendo y desarrollándose un menor. Basándose en esos datos, la doctrina anglosajona entiende que el alto número de mujeres a las que se les otorga la custodia de sus hijos/as no siempre encuentra su explicación en un trato favorable por parte de los tribunales hacia ellas, sino que lo que realmente fundamenta esas decisiones es la voluntad de los jueces de mantener el "statu quo" de los menores.

${ }^{67}$ En este caso el padre C.S.A. demanda el cuidado personal a la madre C.C.M. quien en ese preciso instante vive en el extranjero. El Juzgado de Familia otorga el cuidado personal al padre, lo que confirma la Corte de Apelaciones de Rancagua, y la madre recurre de casación en el fondo ante la Corte Suprema. Los hechos del presente caso son los siguientes: los padres de la menor F.C.S.S. pusieron fin a su convivencia cuando la niña tenía un año y once meses, luego de la separación la madre y su hija se van a vivir a Rancagua, a la casa de su abuela materna. El padre mantiene una relación directa y regular todos los fines de semana. De septiembre a noviembre de 2010 la madre se traslada a México por motivos laborales y la niña queda bajo el cuidado del padre, trasladándose a Santiago, viviendo, además, con su abuela paterna. Durante ese tiempo por exigencias de su trabajo, la madre no puede mantener contacto con su hija. De regreso al país, la madre recupera judicialmente el cuidado personal de su hija, volviendo a vivir en Rancagua; quedando la menor al cuidado de la abuela materna; la madre pasa doscientos catorce días fuera del país y el padre está con la menor todos los fines de semana. Desde enero de 2012 el padre se traslada a Rancagua quedando la menor bajo su cuidado por un acuerdo con la madre; desde esa fecha hasta que se dicta la sentencia por parte de la Corte Suprema la menor vive bajo el cuidado del padre, siendo visitada por su madre cada dos meses. La madre quiere llevar a la menor a vivir al extranjero. 
demos que de forma acertada, ante la petición de la madre de trasladar la residencia de la niña a México, deniega tal posibilidad argumentando que la menor ya ha sido sometida a un sinnúmero de cambios; que la madre no ha logrado probar, ni siquiera ha acompañado prueba de que el cambio de vivir en el extranjero será beneficioso para su hija; y que, en definitiva, la niña se encuentra adaptada a su ciudad, a su colegio y a la compañía del padre y de las abuelas paterna y materna, por lo cual ha logrado el equilibrio y la estabilidad necesarias para su mejor desarrollo ${ }^{68}$.

En este mismo sentido se pronunció la propia Corte Suprema en su sentencia de 14 de julio de 2014. En el caso de autos, el tribunal ad quem consideró que resultaba pertinente mantener el statu quo respecto de la situación de hecho en que se encontraba el niño, niña o adolescente concernida a su cuidado personal por parte de la persona que a la época, lo ejercía, siempre que se resguardara su interés superior ${ }^{69}$.

También en esa misma línea argumental se había pronunciado ya con anterioridad -y bajo la vigencia de la reforma del Código Civil introducida por la Ley 20.680- la Corte de Apelaciones de La Serena, en Sentencia de 12 de agosto de 2013. Efectivamente, el tribunal ad quem dictaminó que debía mantenerse el cuidado personal de las dos hijas menores de edad con el padre, fundamentando tal decisión en la estabilidad tanto económica como personal que hasta el momento el padre les ha venido brindando sin que existiera reproche alguno en tal cometido; y, por ende, una alteración de esa situación hubiera sido absolutamente perjudicial para las niñas e iría en contra de su interés superior ${ }^{70}$.

Un cuarto aspecto a valorar, hace referencia a la vinculación afectiva entre el hijo y su padre o madre, y la relación con sus parientes cercanos (artículo 225-2, apartado a y 229, apartado a, ambos del Código Civil). La inexistencia de relación entre uno de los progenitores y su hijo o hija o la despreocupación demostrada por alguno de ellos con respecto a sus retoños, no debiera ser considerada por sí sola como fundamento para privar del derecho de relación a padres e hijos, pero sí como un factor razonable a evaluar para determinar, por ejemplo, a quién se concede el cuidado personal del menor y la extensión del régimen de relación directa y regular ${ }^{71}$.

Efectivamente, la Corte Suprema, en sentencia de 10 de septiembre de 2014, rechazó el recurso de casación en el fondo intentado por un padre contra la resolución de la

\footnotetext{
${ }^{68}$ Etcheberry se muestra crítica con esta resolución judicial al considerar que el legislador chileno da, en el artículo 225-2 del Código Civil, a lo menos nueve criterios que deben servir para definir el interés superior y justificar el porqué la menor se debe quedar con uno de sus progenitores, y en cambio en el caso en cuestión la Corte se refiere solo a uno de ellos. ETCHEBERry (2014) p. 318.

69 En este supuesto de hecho una madre reclama tanto en primera instancia como en apelación el cuidado personal de su hija otorgado al padre en virtud de un acuerdo alcanzado entre ambos progenitores. Es en este contexto en el que la Corte Suprema concluye, atendiendo tanto al statu quo en que se encontraba la menor como al pacto existente entre los padres, que desestimando el recurso de casación planteado en el fondo.

70 La Corte de Apelaciones de La Serena, en Pincay Cedeño con Alcivar Giler (2013), establece que “...En todo caso, por ahora, convence por sobre todo a estos sentenciadores, que dada la situación de angustia que han debido soportar las niñas con ocasión a las desavenencias de sus padres, resulta aconsejable, para dar alguna estabilidad al convivir de las hijas, especialmente respecto a la menor de ellas, que continúe al cuidado personal del padre respecto de quien no existe reproche en tal cometido".

71 ACuÑa (2014) pp. 175-176.
} 
Corte de Apelaciones de Santiago en la que se aceptaba la petición planteada por la madre, y en consecuencia, se autorizaba la salida del país de la hija de ambos para que residiera en el extranjero, más concretamente en la República de Sudáfrica, hasta el 31 de diciembre de 2017, debiendo retornar al país cada ciento ochenta días y permanecer al menos quince días para mantener el contacto con su padre y familia extendida. Uno de los motivos que impulsó a la Corte de Apelaciones de Santiago -aspecto este ratificado posteriormente por la Corte Suprema- a tomar tal decisión fue que el padre, además de residir fuera de Chile, en ningún momento instó la regulación judicial de un régimen de relación directa y regular con su hija, ni tampoco trató de arribar a acuerdo convencional alguno en ese sentido, lo que denotaba claramente que no había mantenido con su hija una comunicación plena y efectiva durante los últimos tiempos -falta clara de relación afectiva entre padre e hija, esencial para el desarrollo integral de la pequeña $-^{72}$.

En quinto lugar, también debe ponderarse oportunamente el valor de los acuerdos alcanzados por los padres antes y durante el respectivo juicio (artículo 225-2, apartado b y 229, apartado c, ambos del Código Civil). Así, conforme al propio artículo 225-1 del Código Civil los padres pueden acordar un régimen de cuidado individual o compartido; y por su parte, el Juez puede determinar que el cuidado personal lo ejerza uno de los padres o un tercero (artículos 225 y 226 del Código Civil).

Por último, recordar que la lista que acabamos de analizar no es ni mucho menos un sistema cerrado de indicadores. Ello significa, por tanto, que otros factores pueden ser tomados en consideración por parte de los tribunales. Tanto el artículo 225-2 como el 229 del Código Civil finen con una cláusula abierta que se pronuncia del siguiente tenor literal "cualquier otro antecedente -o elemento- que sea relevante atendido el interés superior del hijo". En este apartado podrían incluirse las demandas y deseos de los padres, así como la conducta, carácter, estilo de vida y prácticas sociales de los mismos. También tendrían cabida los antecedentes delictivos, psicológicos o adictivos de los progenitores, así como el estado de salud y otras circunstancias personales concretas de los menores.

\section{ALGUNAS CONCLUSIONES}

La cláusula del interés superior del niño tiene su origen, al contrario de lo comúnmente considerado, en la normativa civil doméstica de determinados estados europeos (Francia, Italia, Reino Unido), y es precisamente de ese acervo dispositivo interno del que trae causa su posterior recepción a nivel internacional: desde su embrionaria acogida en la Declaración de Ginebra (1924), pasando por su mención formal en la Declaración de los Derechos del Niño (1959), hasta su definitivo reconocimiento y desarrollo en la Conven-

\footnotetext{
72 Los sentenciadores del fondo de este caso también concluyeron que a la luz del principio orientador en materia de familia -se están refiriendo, por supuesto, al concepto jurídico indeterminado del interés superior del niño- la salida del país de la niña no era perniciosa, sino que, por el contrario, se observaba como una experiencia que en el futuro podía traerle beneficios en el aspecto personal, "porque la vida en un país desarrollado como es Sudáfrica, donde tendrá acceso a educación y salud de excelente calidad, unido a un entorno multicultural e internacional, le permitirá que en los próximos tres años aprenda un nuevo idioma y conozca realidades socioculturales diferentes, que, de otra forma, le serían imposibles".
} 
ción sobre los Derechos del Niño (1989) y en la Observación General núm. 14 del Comité de los Derechos del Niño (2013).

Tras unos principios dubitativos, en que esta cláusula general no pareció alcanzar, ni por asomo, toda la amplitud o extensión que le son posibles, véanse a título de ejemplo el cúmulo de críticas que recayeron en este sentido sobre la Declaración Universal de los Derechos del Niño (1959), con la ulterior aprobación de la Convención sobre los Derechos del Niño (1989) se dio entrada definitiva, por fin, a la conceptualización del interés superior del niño como principio transversal rector de todas y cada una de las actuaciones e intervenciones, tanto públicas como privadas, dirigidas u orientadas a las personas menores de edad.

Efectivamente, el interés superior del niño, tal y como aparece configurado en el artículo 3, párrafo primero, del texto de la Convención, debe ser tomado en consideración en todas las decisiones y medidas que se adopten relacionadas, directa o indirectamente, con los niños, niñas o adolescentes, ya sean estos individual, grupal o colectivamente contemplados.

Asimismo, este Tratado internacional, verdadero estatuto universal de la niñez, entiende que el principio del interés superior del niño debe ser "uno", eso sí de particular significación, y no el "único" a sopesar cuando los intereses de las personas menores de edad estén en juego.

Una vez determinado el marco internacional de referencia, por lo que al ordenamiento jurídico civil chileno se refiere, la cláusula del interés superior del niño se ha configurado como un concepto jurídico indeterminado, con remisión, para su precisión efectiva, al momento y a la persona encargada de su aplicación, con la correspondiente adecuación del mandato legal a cada caso concreto que pudiere plantearse.

El mentado principio tiene, por tanto, en el Derecho civil chileno, una composición necesariamente genérica, abierta y flexible, lo que permite su aplicación a las diversas situaciones jurídicas y sociales que se planteen como consecuencia de la variada realidad social que de antemano no puede ser prevista en su totalidad y a los cambios que vayan suscitándose con el devenir del tiempo.

Estas pautas y criterios deben apoyarse ineludiblemente en la consideración del niño, niña y adolescente como persona y como ciudadano y, como tal, deben serle reconocidos y garantizados sus derechos fundamentales, su dignidad y el respeto al libre desarrollo de su personalidad, teniéndose siempre en cuenta sus necesidades particulares ${ }^{73}$.

Finalmente, destacar en Chile la técnica legislativa utilizada por el llamado a aplicar el concepto jurídico indeterminado del interés superior del niño: precisar primero el significado y el contenido del concepto (qué es o en qué consiste el interés del menor) y a continuación, comprobar en qué situación y en qué circunstancias concretas de las posibles se

73 Nos recuerda López que relacionado con la edad y madurez del menor está el denominado principio de la autonomía progresiva, en virtud del cual, si bien deben tenerse en cuenta las opiniones de las personas menores de edad, no es menos cierto que la edad y la madurez son dos aspectos relevantes a considerar, más aún por el hecho de que van variando a lo largo del tiempo, lo que permite darle cada vez mayor valor, precisamente, a esa opinión. López (2007) p. 47. Asimismo, Lathrop tratando el tema de la autonomía progresiva de niños, niñas y adolescentes frente a la disposición de ciertas proyecciones de su derecho a la imagen, manifiesta que la "representación" debiera ser la regla excepcional, puesto que el reconocimiento y protección de los diversos estadios evolutivos de las facultades de las personas menores de edad, exige otorgar mayor protagonismo a estos últimos en la celebración de estos actos. LATHrop (2013) p. 944. 
da lo que más conviene a una persona menor de edad en particular. Este sistema, además, otorga una relevancia inusitada a los datos y a las circunstancias del caso concreto, porque estos son los que le van a permitir, en definitiva, encontrar la solución adecuada dentro del ámbito de apreciación o zona de variabilidad del concepto jurídico indeterminado que se sitúa en la llamada "zona de opciones razonables" o "halo conceptual”.

No obstante lo apuntado, en los últimos años y para dotar al sistema de mayor seguridad jurídica, se ha operado en el ordenamiento jurídico chileno un giro copernicano hacia técnicas legislativas más propias de los sistemas normativos anglosajones, más favorables o que optan por la concreción de situaciones que consideran que redundan en interés de las personas menores de edad.

\section{BIBLIOGRAFÍA CITADA}

Acuña San Martín, Marcela (2011): Efectos jurídicos del divorcio (Santiago de Chile, AbeledoPerrot - Thomson Reuters) 461 pp.

Acuña SAn Martín, Marcela (2014): Derecho de relación directa y regular (Santiago de Chile, LegalPublishing, Thomson Reuters).

Adroher Biosca, Salomé (1999): "La protección de los menores inmigrantes, refugiados y desplazados en el Derecho español", Revista del Ministerio de Trabajo y Asuntos Sociales, No 15: pp. 27-46.

Aguilar Caballo, Gonzalo (2008): "El principio del interés superior del niño y la Corte Interamericana de Derechos Humanos", Estudios Constitucionales, No 1: pp. 223-247.

Alonso Pérez, Mariano (1997): "La situación jurídica del menor en la Ley Orgánica 1/1996, de 15 de 15 de enero, de protección jurídica del menor, de modificación del Código Civil y de la Ley de Enjuiciamiento Civil: luces y sombras", Actualidad Civil, No 2: pp. 17-40.

Alston, Philip (1994): The best interest of the child. Reconciling culture and human rights (Oxford, Clarendon Press) 325 pp.

Alston, Philip (1996): “The best interest of the child. Towards a synthesis of children's rights and cultural values", Simposio Internacional: La Convención de los Derechos del Niño hacia el siglo XXI (Salamanca, Universidad de Salamanca) pp. 240-263.

Baeza Concha, Gloria (2001): "El interés superior del niño: derecho de rango constitucional. Su recepción en la legislación nacional y aplicación en la jurisprudencia”, Revista Chilena de Derecho, Vol. 28 No 2: pp. 355-362.

Bromley, P. M. (1987): Bromley's Family Law (London, Butterworths) 368 pp.

Buirette, Patricia (1990): "Réflexions sur la Convention Internationale des Droits de l'Enfant”, Revue Belge de Droit International, No 1: pp. 57-78.

Carbonnier, Jean (1960): “Comment. S. Cour d'Appel Paris, 10 de abril de 1959”, Dalloz, No 1: pp. 650-673.

Cillero Bruñol, Miguel (1994): "Evolución histórica de la consideración jurídica de la infancia y la adolescencia en Chile", en PiLотті, Francisco (edit.), Infancia en riesgo social y políticas sociales en Chile (Montevideo, Instituto Interamericano de la Niñez) pp. 75-138.

Cillero Bruñol, Miguel (1999): "El interés superior del niño en el marco de la Convención internacional sobre los Derechos del Niño”, Justicia y Derechos del Niño, No 1: pp. 48-62. 
Cretney, Stephen Michael (1979): Principles of Family Law (London, Sweet and Maxwell) $528 \mathrm{pp}$.

Davis, Sandra y Rosenblatt, Jeremy (1993): International child abduction (London, Sweet and Maxwell) $246 \mathrm{pp}$.

De Mario y Gómez-Sandoval, Belén (1999): "Las adopciones transnacionales", La Ley, No 4747: pp. 1-8.

Del Picó Rubio, Jorge (2010): Derecho matrimonial chileno (Santiago de Chile, AbeledoPerrot - LegalPublishing) $484 \mathrm{pp}$.

Desper, J. Louise (1957): Enfants du divorce (Paris, Presses Universitaires de France) 220 pp.

Díaz de Valdés, José Manuel (2010): "Un marco constitucional para los tratamientos médicos de niños, niñas y adolescentes”, Revista Chilena de Derecho, Vol. 37 No 2: pp. 271-310.

Dogliotti, Massimo (1992): "Che cosa è l'interesse del minore?", Il Diritto di Famiglia e delle Persone, No 4: pp. 1085-1097.

EekelaAr, John (1992): Regulating divorce (London, Clarendon Press) 278 pp.

Esplugues, Carlos (1997): "El nuevo régimen jurídico de la adopción en España”, Rivista di Diritto Internazionale Privato e Processuale, No 1: pp. 33-74.

Etcheberry Court, Leonor (2014): "Comentario de jurisprudencia. Derecho de Familia. Corte Suprema, cuidado personal, 13 de febrero de 2014, Rol 10358-2013”, Revista Chilena de Derecho Privado, No 22: pp. 315-318.

Fernández Masía, Enrique (1998): "Las entidades públicas y la protección de los menores extranjeros en España”, Actualidad Civil, No 19: pp. 427-451.

ForTin, Jane (2009): Children's Rights and the developing law (Cambridge, Cambridge editions) $357 \mathrm{pp}$.

García de Enterría, Eduardo y Fernández, Tomás-Ramón (2000): Curso de Derecho Administrativo I (Madrid, Civitas) 680 pp.

García de EnTERría, Eduardo (1962): "La lucha contra las inmunidades del poder en el Derecho administrativo", Revista de Administración Pública, No 38: pp. 159-208.

Gatica, Nora y Chaimovic, Claudia (2002): "La justicia no entra en la escuela. Análisis de los principales principios contenidos en la Convención sobre los Derechos del Niño", La Semana Jurídica, del 13 al 19 de mayo de 2002.

Giménez-Salinas y Colomer, Silvia (1998): La adopción: un estudio comparado (Barcelona, Ed. Centro de Estudios Jurídicos de la Generalitat de Cataluña) 255 pp.

Gómez de la Torre Vargas, Maricruz (2000): "El interés superior del niño", Gaceta Jurídica, No 328: pp. 23-26.

GonzÁlez Beilfuss, Cristina (1996): "La aplicación en España del Convenio de La Haya de 29 de mayo de 1993 relativo a la protección del niño y a la cooperación en materia de adopción internacional", Revista Jurídica de Cataluña, No 2: pp. 313-346.

Gutiérrez García, Carlos y Martí Sánchez, José María (2000): "Los derechos del menor: evolución y situación actual", Revista Jurídica de Castilla La Mancha, No 28: pp. 27-39.

Lathrop Gómez, Fabiola (2005): Cuidado personal de los hijos. Análisis de la Ley de matrimonio civil y Tribunales de Familia (Santiago de Chile, Punto Lex S.A.) 160 pp.

LATHrop GÓMEZ, Fabiola (2013): "El derecho a la imagen de niños, niñas y adolescentes en Chile: una mirada crítica a la luz del Derecho internacional de los derechos humanos y 
de los estatutos normativos iberoamericanos de protección integral de la infancia y la adolescencia”, Revista Chilena de Derecho, Vol. 40 No 3: pp. 929-952.

LÁZARO GonZÁlez, Isabel (2002): Los menores en el derecho español (Madrid, Tecnos) 635 pp.

Lovera Parmo, Domingo (2009): "Libertad de expresión e interés superior del niño, a propósito de la Sentencia de la Corte de Apelaciones de Antofagasta de 6 de marzo de 2009 y Corte Suprema de 23 de abril de 2009”, Revista Chilena de Derecho Privado, No 12, pp. 215-225.

Longobardo, Tilde (1991): "La Convenzione internazionale sui Diritti del Fanciullo", Il Diritto di Famiglia e delle Persone, No 1: pp. 370-427.

López Díaz, Carlos (2007): Manual de Derecho de Familia y Tribunales de Familia (Santiago de Chile, Librotecnia, Tomo I) 216 pp.

Martín GonzÁlez, Manuel (1967): "El grado de indeterminación legal de los conceptos jurídicos”, Revista de Administración Pública, No 54: pp. 270-298.

Meliá Llácer, Reyes (1989): "La protección internacional de los derechos del niño", Revista General del Derecho, No 536: pp. 2907-2927.

Miralles Sangro, Pedro Pablo (1989): El secuestro internacional de menores y su incidencia en España. Especial consideración del Convenio de La Haya de 1980 (Madrid, Ministerio de Asuntos Sociales) 280 pp.

MnOOKIn, Robert (1985): In the interest of children: advocacy, law reform and public policy (New York, W. H. Freeman and Co.) 235 pp.

Newell, Peter y Hodgkin, Rachel (1998): Implementation Handbook for the Convention on the Rights of the Child (New York, Unicef) $701 \mathrm{pp}$.

Orrego Acuña, Juan Andrés (2007): Temas de Derecho de Familia (Santiago de Chile, Sociedad Editora Metropolitana) $452 \mathrm{pp}$.

Pérez Vera, Elisa (2000): “Convenio núm. XVIII de la Conferencia de La Haya sobre los aspectos civiles de la sustracción internacional de menores, de 25 de octubre de 1980 e informe explicativo del Convenio", Suplemento del Boletín del Ministerio de Justicia, No 1865: pp. 1120-1165.

Pettigiani, Eduardo Julio (1998): "El interés superior del menor, ¿es superior a todo interés?”, Ponencia del X Congreso Internacional de Derecho de Familia: El niño como sujeto de derecho (Mendoza, Universidad de Cuyo) pp. 11-21.

Picontó Novales, Teresa (1996): La protección de la infancia. Aspectos sociales y jurídicos (Zaragoza, Egido) 317 pp.

Puente Alcubilla, Verónica (2001): Minoría de edad, religión y derecho (Madrid, Ministerio de Trabajo y Asuntos Sociales) 416 pp.

RavetLlat Ballesté, Isaac (2012): "El interés superior del niño: concepto y delimitación del término", Educatio siglo XXI, No 2: pp. 89-108.

Rivero Hernández, Francisco (2007): El interés del menor (Madrid, Dykinson) 253 pp.

Roca Trias, Encarna (1994): "El interés del menor como factor de progreso y unificación del Derecho Internacional Privado”, Revista Jurídica de Cataluña, No 4: pp. 915-992.

Rodríguez Pinto, María Sara (2009): "El cuidado personal de niños y adolescentes en la familia separada: criterios de resolución de conflictos de intereses entre padres e hijos en el nuevo Derecho chileno de familia", Revista Chilena de Derecho, Vol. 36 No 3: pp. 545-586. 
Rubellin-Devichi, Jacqueline (1996): "Le principe de l 'intérêt de l'enfant dans la loi et la jurisprudence Françoise”, Simposio Internacional: La Convención de los Derechos del Niño hacia el siglo XXI (Salamanca, Universidad de Salamanca) pp. 318-322.

SAInZ Moreno, Fernando (1976): Conceptos jurídicos, interpretación y discrecionalidad administrativa (Madrid, Civitas) $230 \mathrm{pp}$.

Uhía Alonso, Josefa María (1998): "Problemática de tipo legal derivada de la adopción internacional”, La Ley, No 4480: pp. 1960-1966.

Van Bueren, Geraldine (1995): The international law on the rights of the child (Dordrecht, Martinus Nijhoff) 234 pp.

Villagrasa Alcaide, Carlos (2012): Comments on the reports of the Committee on the Rights of the Child. Foreword (Barcelona, Huygens) 40 pp.

\section{JURISPRUDENCIA CITADA}

\section{Corte Suprema}

Martínez Vicencio con Pávez Cáceres (2014): Corte Suprema, 6 de octubre de 2014 (CL/ JUR/7101/2014).

Benavides Santelices con Salinas Garrido (2014): Corte Suprema, 14 de julio de 2014 (CL/ JUR/4459/2014).

Willem Hekman con Orellana González (2014): Corte Suprema, 17 de septiembre de 2014 (CL/JUR/6646/2014).

Coronado Cea con Carrillo Maraboli (2014): Corte Suprema, de 10 de septiembre de 2014 (CL/JUR/410/2013).

Solís Arredondo con Soto Muñoz (2013) Corte Suprema, 13 de febrero de 2014, Rol No 10.358-2013.

Herrera Porras con Gálvez Herrera (2013): Corte Suprema, 14 de enero de 2013 (CL/ JUR/88/2013).

Roblero Hidalgo (2011): Corte Suprema, 11 de abril de 2011 (CL/JUR/3091/2011).

Arriola y Donoso con Tapia (2008): Corte Suprema, de 15 de julio de 2008, Rol No 3202-08.

Heyner Mena con Capdeville Arrate (2012): Corte de Apelaciones de Santiago, 9 de octubre de 2012 (CL/JUR/2279/2012)

Pincay Cedeño con Alcivar Giler (2013): Corte de Apelaciones de la Serena, 12 de agosto de 2013 (CL/JUR/3315/2013).

Coronado Cea con Carrillo Maraboli (2013): Corte de Apelaciones de Concepción, 21 de febrero de 2013 (CL/JUR/410/2013).

Bravo Mujica con Liceo Experimental Artístico y de Aplicación (2009): Corte de Apelaciones de Antofagasta, 6 de marzo de 2009, Rol No 36.

Sentencia de la Corte de Apelaciones de San Miguel, de 30 de noviembre de 2009.

Forneron Vs. Argentina (2012): Corte Interamericana de Derechos Humanos, Sentencia de 27 de abril de 2012.

Atala Riffo Vs. Chile (2012): Corte Interamericana de Derechos Humanos, Sentencia de 24 de febrero de 2012. 